\title{
To move home or move on? Investigating the impact of recovery aid on migration status as a potential tool for disaster risk reduction in the aftermath of volcanic eruptions in Merapi, Indonesia
}

Jonathan A. Muir

The Ohio State University

Michael R. Cope

Brigham Young University - Provo, michaelrcope@byu.edu

Leslie R. Angeningish

Institute of Community Development

Follow this and additional works at: https://scholarsarchive.byu.edu/facpub

den Ef thackson

Brigham Young University - Provo

\section{Original Publication Citation}

Muir1 , Jonathan A., Michael R. Cope, Leslie Angeningsih, and Jorden E. Jackson1 . 2020. “To Move Home or Move On? Investigating the Impact of Recovery Aid on Migration Status after Volcanic Eruptions in Merapi, Indonesia." International Journal of Disaster Risk Reduction, 46(June): 101478.

\section{BYU ScholarsArchive Citation}

Muir, Jonathan A.; Cope, Michael R.; Angeningish, Leslie R.; and Jackson, Jorden E., "To move home or move on? Investigating the impact of recovery aid on migration status as a potential tool for disaster risk reduction in the aftermath of volcanic eruptions in Merapi, Indonesia" (2020). Faculty Publications. 4082. https://scholarsarchive.byu.edu/facpub/4082

This Peer-Reviewed Article is brought to you for free and open access by BYU ScholarsArchive. It has been accepted for inclusion in Faculty Publications by an authorized administrator of BYU ScholarsArchive. For more information, please contact ellen_amatangelo@byu.edu. 


\title{
To move home or move on? Investigating the impact of recovery aid on migration status as a potential tool for disaster risk reduction in the aftermath of volcanic eruptions in Merapi, Indonesia
}

\author{
Jonathan A. Muir ${ }^{\mathrm{a}, *}$, Michael R. Cope ${ }^{\mathrm{b}}$, Leslie R. Angeningsih ${ }^{\mathrm{c}}$, Jorden E. Jackson ${ }^{\mathrm{b}}$ \\ a The Ohio State University, USA \\ ${ }^{\mathrm{b}}$ Brigham Young University, USA \\ c Institute of Community Development "APMD", USA
}

\section{A R T I C L E I N F O}

\section{Keywords:}

Disasters

Internal displacement

Migration

Recovery aid

And risk reduction

\begin{abstract}
A B S T R A C T
Disasters are associated strongly with forced migration. Indeed, migration is a standard survival strategy for those facing disruptions of this kind. Such is the case with Mt. Merapi, Indonesia, where a series of eruptions occurred in 2010. Mechanisms related to forced migration in such scenarios are fairly well understood, yet it remains less clear what factors may influence return migration. Given local interest in facilitating resettlement out of hazardous areas as a means of risk reduction, our objective in this study is to explore the extent to which recovery aid may create incentives for households to move on rather than move home. Specifically, we explore whether the influence of recovery aid varied by whether it was: financial vs. another type of aid; provided by a government agency or NGO versus a social network; and/or distributed with other types of recovery aid. We use data from a cross-sectional pilot study and multinomial logistic regression models to explore the influence of aid on migration status. Of the various forms of aid considered, financial recovery aid was consistently associated with moving on. The combination of financial recovery aid with remittances resulted in an association with having moved on that was even stronger than just receiving financial recovery aid. Ultimately, analyses of "aid packages" suggest that a combination of aid was relatively more effective in fostering resettlement, suggesting that while other forms of aid may not have been sufficient to increase resettlement by themselves, they may enhance the effect of financial recovery aid.
\end{abstract}

\section{Introduction}

Between October 26th and November 5th, 2010, a series of violent volcanic eruptions impacted the region surrounding Mt. Merapi in Central Java, Indonesia. Over time, these eruptions culminated in repeated discharges of ash and lava, as well as the formation of large eruption columns that sent several pyroclastic flows into heavily populated areas located along the slopes of the volcano. The seismic activity was accompanied by heavy rainfall that produced highly destructive lahars. The scale of the $2010 \mathrm{Mt}$. Merapi eruptions exceeded that of the $1872 \mathrm{Mt}$. Merapi eruption, previously the largest eruption on record for this volcano. Prior to the onset of these eruptions, the Indonesian government raised its alert to its highest level and issued evacuation orders that affected 19,000 people. In total, however, it is estimated that approximately 400,000 people were displaced, 3300 homes/buildings were destroyed, and 383 people were killed.

Because disasters from natural hazards are associated with high risks to both life and property [1,2], they are often associated strongly with forced migration [3-6]; either as a temporary evacuation or as a forced migration of longer duration. Indeed, migration, whether temporary or permanent, is a standard survival strategy for those facing disruptions of this kind [4]. Such is the case with Mt. Merapi where a major eruption occurs every 4-5 years. However, despite the well-known danger, the area surrounding the mountain remains densely populated. More surprisingly, it is also the site of frequent return migrations as households persist in returning to their original communities once the dangers associated with an eruption have subsided [7-10]. Anticipating that patterns of return migration increases the risk for future disaster events in the area surrounding Mt. Merapi, the Indonesian disaster management agency "Badan Nasional Penanggulangan Bencana" (BNPB)

\footnotetext{
* Corresponding author.

E-mail address: muir.53@osu.edu (J.A. Muir).
} 
conducted a risk assessment of the area and thereafter endeavored to reorganize residential areas for the purpose of hazard mitigation [8]. With this goal in mind, the distribution of recovery assistance to victims of the disaster was organized in part to create incentives for households to resettle out of hazardous areas.

Our objective in this study is to explore the extent to which recovery aid was associated with households resettling away from their original community. Drawing on survey data collected from a cross-sectional pilot study in the geographic area surrounding Mt. Merapi after the 2010 volcanic eruptions, we explore the extent to which various forms of recovery aid were associated with migration status, particularly that of respondents indicating that they had subsequently resettled or moved on. Specifically, we explore whether the influence of a given type of recovery aid varied by whether it was:

1. Financial vs. other types of aid (e.g., distribution of food)

2. Provided by government bodies or NGOs versus a household's social network

3. Distributed in combination with other types of recovery aid as part of an "aid package" that include multiple types of aid.

As an exploratory examination of these questions, this study contributes to the literature on migration in the context of disasters from natural hazards through suggesting how recovery aid may influence migration decisions in this context and thereby be used as a tool for future risk reduction.

\section{Theoretical background}

\subsection{Migration}

Migration, broadly defined as a permanent or semi-permanent change of residence [11], is a critical driver of demographic change $[12,13]$. Decisions to migrate are often conceptualized as reflecting a combination of push factors associated with locations of origin, pull factors associated with locations of destination, and intervening obstacles that prevent or delay migration [11]. Recent theories on migration at the individual level are often couched within a framework of rational choice that reflects the push/pull factors individuals take into account, as well as intervening obstacles [1,11,14-16]. Prominent among such frameworks is the focus on economic incentives, in which a dearth of opportunities at an individual's place of origin (i.e., push factors) are juxtaposed with ample opportunities in potential destinations (i.e., pull factors). This is in line with findings from studies of internal migration in Indonesia that found that economic factors were foremost in predicting migration during the 20th century $[17,18]$. Other studies have noted a pattern of internal, and often circular migration within Indonesia [18-21]. As noted by Lindquist [22]; these patterns are captured by the verb "merantau", which is suggestive of relocation with a somewhat vague livelihood purpose while maintaining the possibility of periodic return to one's place of origin. Core frameworks for return migration likewise recognize the importance of economic incentives [23-26], but some also allow for other factors such as geographic, social and political context to play important roles [23,27]. While general migration theories provide a helpful starting point, theories concerning migration in the context of disasters from natural hazards require further refinement. Although migrants in these contexts are still seeking to maximize life outcomes, the primary goal in these situations is often the maintenance of life itself. As such, the factors and mechanism at play deserve further specification.

\subsection{Disasters from natural hazards and migration}

Understanding of migration decisions in the wake of disasters necessitates the consideration of broader macro-level context, particularly the significance of ecological pushes that encourage people to migrate
[1,4,5,27-30]. Hugo addressed these ideas and maintained that in the context of disasters, migration is probably viewed best on a continuum that ranges from totally voluntary migration-in which choice is the decisive element that encourages people to move-to completely forced migration, where the migrants are faced with death if they remain in their present place of residence [4]. The extent to which a migration is more or less forced depends upon the severity of the hazard, perceptions of risk tied to the hazard [31], and the response of macro-level actors, such as government and non-governmental organizations (NGOs) [1,4, 32]. Given that forced migration is by definition less voluntary compared to general migration [33], some indicators that weigh heavily in general migration theory (e.g., gender and age) are not always significant and other indicators (e.g., socioeconomic status) may operate in reverse [33]. This is particularly the case when the severity of the disaster is such that entire populations are forced to migrate. However, the more voluntary the migration, even after a disaster, the more likely it will reflect the characteristics of general migrations [1,4].

Return migration post forced migration requires better understanding [34]. Consistent with general migration theory, prior studies have found that economic incentives often are associated with the likelihood of return migration [35]. Beyond economic incentives, a systematic review [36] identified the habitability of homes, access to affordable housing, financial burdens, the extent of restoration of public services and facilities, and a sense of place and identity as major factors influencing return migration in the aftermath of a disaster. Fear of future disasters, stress associated with recovery, and loss of employment were also influential [36]. Other research has shown that education, employment, and other indicators of socioeconomic status may influence return migration after a disaster resulting from a natural hazard [37]. While return migrants face multiple intervening obstacles to reestablishing themselves successfully in their old communities [34], including the continued perception of risk associated with the previous disaster [31], recovery aid in the aftermath of the disaster may help mitigate various obstacles to returning home; e.g., helping to improve the habitability of damaged homes, restoring public services and facilities, or to relieve stress associated with the disaster.

\subsection{Recovery aid and migration status}

In the context of disasters, governments and NGOs have the potential to act as intervening agents that either inhibit or facilitate migration, both by creating policies concerning return migration [32], and by the extent to which they offer aid to help return migrants reestablish themselves [34]. Herein we opt to focus on the effects of recovery aid on migration.

Federal and international aid can be an incentive for households to remain in their localities rather than migrate away from disaster-prone areas [38]. After a tornado struck North-Central Bangladesh in 1996, decisions to remain in original communities were strongly affected by recovery aid resulting in minimal outmigration [39]. Likewise, after another tornado in 2004, the vast majority of people affected by the disaster still chose to remain in the area [40]. For the most part, recovery aid from government agencies and NGOs in these instances was distributed to households in an equitable manner and surpassed the cost of the damages suffered, thus encouraging those affected by the tornadoes to remain in their communities [40]. Similarly, aid packages were offered as incentives to households and businesses in an effort to curb outmigration after a series of earthquakes hit Christchurch, New Zealand between 2010 and 2011. The vast majority of businesses and organizations chose to remain in Christchurch rather than relocate [41, 42]. These examples indicate that post-disaster aid can create incentives for people to stay in their original communities. Sometimes aid does not act as an incentive to resettle, and can delay recovery processes. Households affected by the 2004 tsunami in Thailand received an adequate amount of aid, but still had a slow recovery [43]. Researchers believe recovery was stalled due to a excess of organizations and 
participants in the recovery process and a lack of coordination between them [43].

Alternatively, recovery aid has also succeeded as a tool for encouraging outmigration from hazardous areas. After massive flooding hit Malaysia, relocation plans were designed to encourage people to move out of flood-prone areas [44]. Because of the high cost of migration, rural peasants were unlikely to migrate if aid was not guaranteed. If aid was guaranteed in the form of a job, home, and/or lands outside of their communities and outside the disaster zone, the people from affected regions were highly likely to migrate [44]. However, because a large number of people were effected by floods, the government was unable to supply enough aid to encourage everyone to leave the hazardous peninsula, resulting in minimal migration [44]. Additionally, a study done on settlement abandonment in Montserrat after a volcanic eruption examined migration and noted that rebuilding and relocation would not have been possible without financial aid from the UK government [45]. For half of the island population, the aid offered by the UK encouraged them to relocate off the island [46]. Of those individuals that chose to migrate, approximately half relocated to other Caribbean islands and half resettled to Great Britain [46]. Thus, aid packages have in some instances been used successfully to encourage people to leave their residence.

Resettlement after a disaster in a developing country can be temporary, especially if resettlement areas are not created with culturally sensitive and community centered designs and processes [47,48]. Post-disaster resettlement is approached two ways-either top down or bottom up [49], and successful resettlement involves coordination between multiple stakeholder and community members [48]. For example, a study examining the resettlement of two fishing villages in Tamilnadu, India, found that housing design, location, clustering, allocation process, distance from previous town, and public space allocation all impacted resettlement success. To avoid temporary resettlement, local needs of accessibility, family typology, proximity to livelihood, and creation of intentional public space with landmarks should be addressed [47]. Another study found that when deciding whether to relocate or move back, tsunami risk was only a minor concern for displaced Indonesians; concerns about costs of rent, land prices, and distance from work were most pressing [49]. Thus, often times for people who experience disaster in a developing country, resettlement is only temporary as other livelihood needs lead people to abandon inadequate resettlement places.

Recovery aid may encourage outmigration when it is slow to reach geographically isolated locations. In Kenya and Somalia, rural and pastoral victims of drought migrated towards towns and city centers because these locations offered food aid and a chance to diversify their livelihood, protecting them from future disasters [50]. Along the same lines, when post-disaster recovery is lacking nationwide, people tend to migrate towards cities. In Ethiopia during times of food shortages, households did not have access to needed aid [51]. Family members choose to migrate to cities and towns where income was higher and job opportunities were more abundant [51]. Additionally, after the earthquake-avalanche in 1970 in Peru, rather than provide loans to rebuild homes, the government chose to build temporary houses and distribute them on a first come first serve basis [52]. The temporary housing, as well as the higher wages promised by the reconstruction committee, attracted increased rural migration. Rural peasant migration continued to city areas where aid was provided even after permanent housing was established and rural non-homeowners were given lowest priority (first, second, and third priority going to landowners and renters) [52].

The findings from these studies suggest that recovery aid can successfully function as a tool for influencing migration decisions, both for increasing probability of return migration as well as for outmigration, depending on how it is organized and distributed. This is particularly the case for cash transfers and other forms of financial recovery aid.

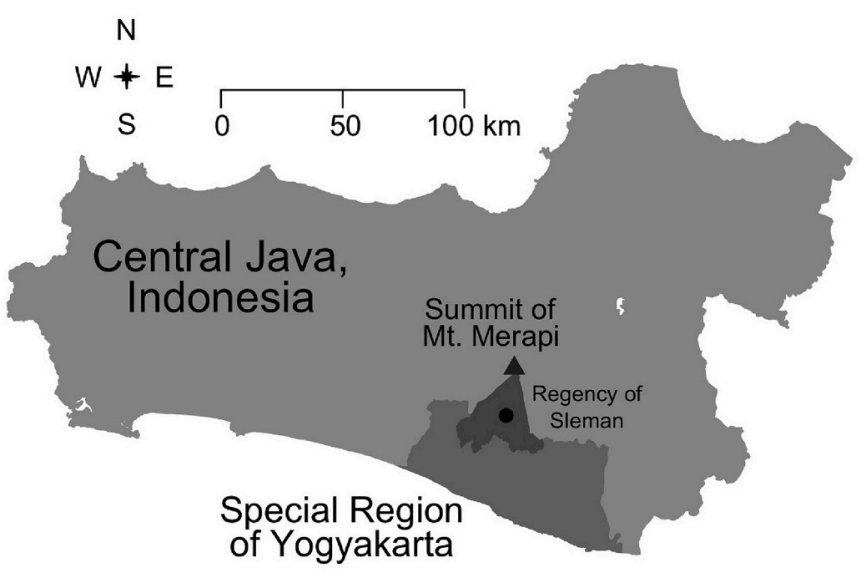

Fig. 1. Mt. Merapi, Indonesia. Located in Central Java province and the Special Region of Yogyakarta.

\subsection{Migration in context: geography, ethnicity, and recovery aid}

Mt. Merapi is located in the central region of Java, Indonesia, the most highly populated island on the planet, with an average population density of 1000 persons per square kilometer (see Fig. 1). Of interest to this investigation, the population density within a $15 \mathrm{~km}$ radius of Mt. Merapi ranges from 0 to 5000 per square kilometer. Within this geographic area, roughly $98 \%$ of the population are ethnic Javanese [58]. A common Javanese proverb, 'Sedumuk batuk senyari bumi', is interpreted to mean that 'dignity and land are things to strive for'. The proverb highlights the place attachment that Javanese people have to their land and community.

This attachment has been highlighted as part of the explanation for some Merapi residents choosing to return to their original villages despite the well known risks associated with living on the slopes of the volcano $[8,9]$. In line with this, past studies have documented multiple area in Indonesia where residents, in spite of well-documented risks and official relocation policies, are reluctant to move $[7,10,59,60]$. Of particular note to our study, Sontosudarmo [10] and Amin et al. [7] have showed that, though threatened by the eruption of Mt. Merapi that takes place periodically every $4-5$ years, residents choose to remain in the area. As Amin et al. [7]; 35) explains, residents "understand that disaster is something dangerous but an attempt to leave their place is not something they have to do because they have an attachment to Merapi as a place of origin, where they gain a sense of comfort and safety." Thus emerges a pattern of return migration in which displaced residents persist in returning to their communities and homes once the immediate risks of a disaster subside.

However, recognizing that these patterns of return migration likely increase the risk for future disaster events in the area surrounding Mt. Merapi, BNPB, in collaboration with other government agencies, endeavored to reorganize residential areas for the purpose of hazard mitigation in the aftermath of the 2010 eruptions. For this purpose, a risk analysis was carried out that identified the southern slopes of Mt. Merapi as those at highest risk [8] and in line with these findings, the government sought to encourage villagers living along Mt. Merapi's southern slopes to relocate to less hazardous areas. With this goal in mind, the central government, through BNPB, promised to give recovery assistance to victims of the disaster. The total amount of recovery assistance was based on the level of damages that an individual/household experienced in connection to the disaster. Damage level was classified into mild, moderate or completely destroyed. People whose houses were completely destroyed were to be relocated and receive permanent housing. While waiting to receive the promised recovery assistance, people lived in temporary housing or shelters. Disaster victims were given a transition period of two years during 
which time they could stay in their temporary residence, after that, they would have to make a decision whether or not they were willing to relocate.

\subsubsection{Financial recovery aid: evidence of efficacy}

Cash transfers and other forms of financial recovery aid can be effective forms of recovery aid in general, as it can help people meet their immediate needs in the wake of a disaster or crisis $[53,54]$. Studies evaluating the relative efficacy of cash based recovery aid indicate that these interventions can, under the proper circumstances, effectively achieve a wide range of objectives; e.g., improving access to food and thereby helping families smooth consumption patterns, improving access to shelter, and reducing the extent to which families rely upon negative coping strategies during a crisis (e.g., dietary restriction or child labor) $[53,55]$. However, its relative efficacy is context specific and depends upon the type of financial aid, its relative value, who are the targeted recipients, how the recovery aid intervention is organized, and ultimately the effectiveness of implementing the intervention [53-57]. Moreover, it depends upon broader contexts such as the continued presence of markets in which the financial aid can be used to obtain a variety of goods or services.

Perhaps the greatest advantage of financial recovery aid is that it is a flexible tool for improving the welfare of individuals and households that empowers them to meet their specific needs based upon their own assessment of what those needs are at the time [53-55]. As Johnson and Krishnamurthy [54] highlight, "Extending the freedom to choose puts critical decisions about household needs and investments squarely in the hands of the household, whose members are in theory best placed to assess the needs that are most pressing at a particular point in time (e.g. consumption smoothing in order to invest in fodder for livestock)." The downside to this increased autonomy is the loss of control on the part of the providing agency or organization over how the financial assets are used, thus the increased popularity of "conditional cash transfers" that stipulate specific behavioral requirements that must be met to qualify for the assistance [54]. One possible application of such conditions is to facilitate the resettlement of individuals and households out of hazardous areas.

In their review of evidence concerning the efficacy of social protection programs to facilitate resilience to disaster, Johnson and Krishnamurthy [54]; 653) outline seven mechanisms through which cash based social protection programs may facilitate migration. Of the seven proposed mechanisms, four are likely applicable to the present study. First, these program may facilitate migrants in connecting with new labor markets that are reliable and sustainable alternatives to those in their sending communities-this is a particularly powerful mechanism for the present study considering the role of place attachment in the pattern of return migration in the Mt. Merapi area. Second, these programs can help offset the opportunity costs of relocation such as compensation for assets and incomes lost as a result of resettlement. Third, financial recovery aid interventions can subsidize the actual costs of relocation; i.e., "cash and conditional cash transfers can be used to cover relevant costs of moving family members and household possessions ..." [54]; 653). Finally, these programs can support the broader social networks, such as the communities and local authorities tasked with receiving and resettling the displaced migrants.

\section{Summary \& research hypotheses}

The migration literature suggests that economics often plays an important role in migration decisions. With regards to migration in the context of disasters, the literature suggests that factors associated with disasters (e.g., the extent of damage caused by the disaster) are associated strongly with migration decisions. In addition, recovery aid may also influence migration decisions. Depending on how it is organized and distributed, recovery aid may increase the probability of return migration or alternatively for outmigration. In the case of Mt. Merapi,

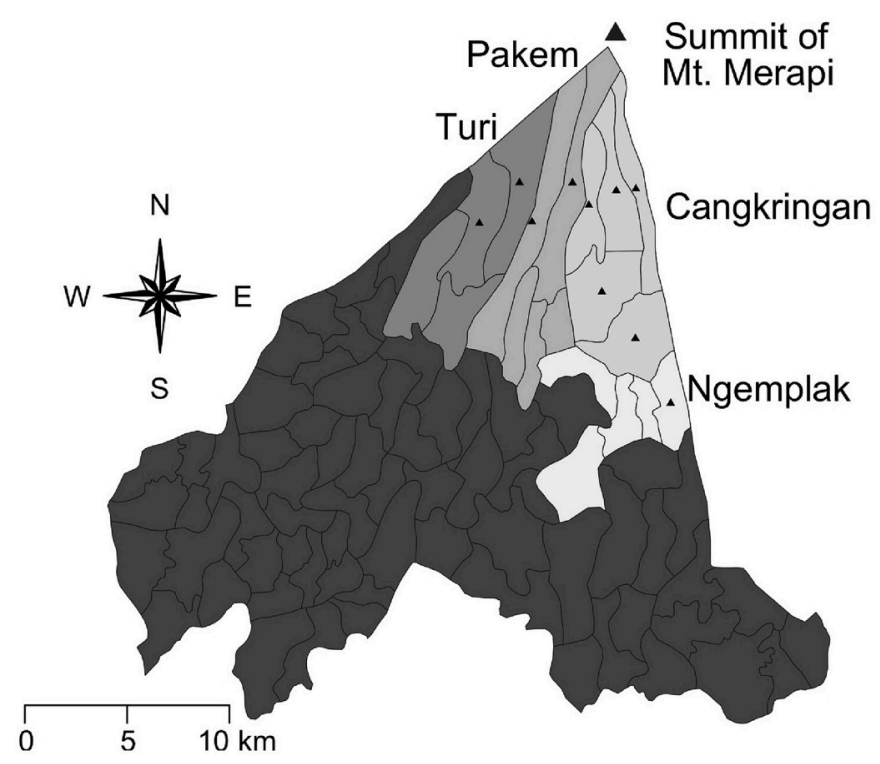

Fig. 2. Regency of sleman.

the distribution of recovery assistance to victims of the disaster was organized in part to create incentives for households to resettle out of hazardous areas [8]. With this in mind, we propose the following hypotheses:

1. The overall provision of recovery assistance will be associated with resettlement.

2. Economic recovery assistance in the form of financial aid or remittances will create the strongest incentive for resettlement.

3. Aid "packages" that combine multiple forms of assistance-e.g, financial, food, health, or remittances-may create stronger incentives for resettlement compared to any type of aid provided in isolation as they may more comprehensively address costs of resettling to new locations.

\section{Data and methods}

To address our research questions, we drew on data from the "Community Recovery after a Natural Disaster: A Survey of Communities Affected by Mt. Merapi Eruptions" study. The survey questionnaire used in the study was developed in an iterative process by a research team including members from Indonesia and the United States. After initial development in English, the questionnaire was translated into Bahasa Indonesia by a translation team made up of research team members who were native speakers of either Bahasa Indonesia or English, but who were also fluent in their non-native language of either Bahasa Indonesia or English. The translation process included standard translation/back-translation steps in an effort to increase the accuracy and cultural appropriateness of the questionnaire. The data were collected by student research assistants and faculty at the Institute of Community Development Research Center, Yogyakarta, Indonesia. All interactions between the researchers and respondents were carried out in Bahasa Indonesia, and data were then translated into English and entered into a database for further statistical analysis.

The study was conducted 16 months after the 2010 eruptions. It was organized as a pilot study to document the experiences of victims of the disaster; including their experiences related to disaster preparedness, mitigation, and recovery, as well as their overall experience of the emergency. This has important implications for the overall power, or limitations, of the data collected to investigate migration in response to the eruptions. 


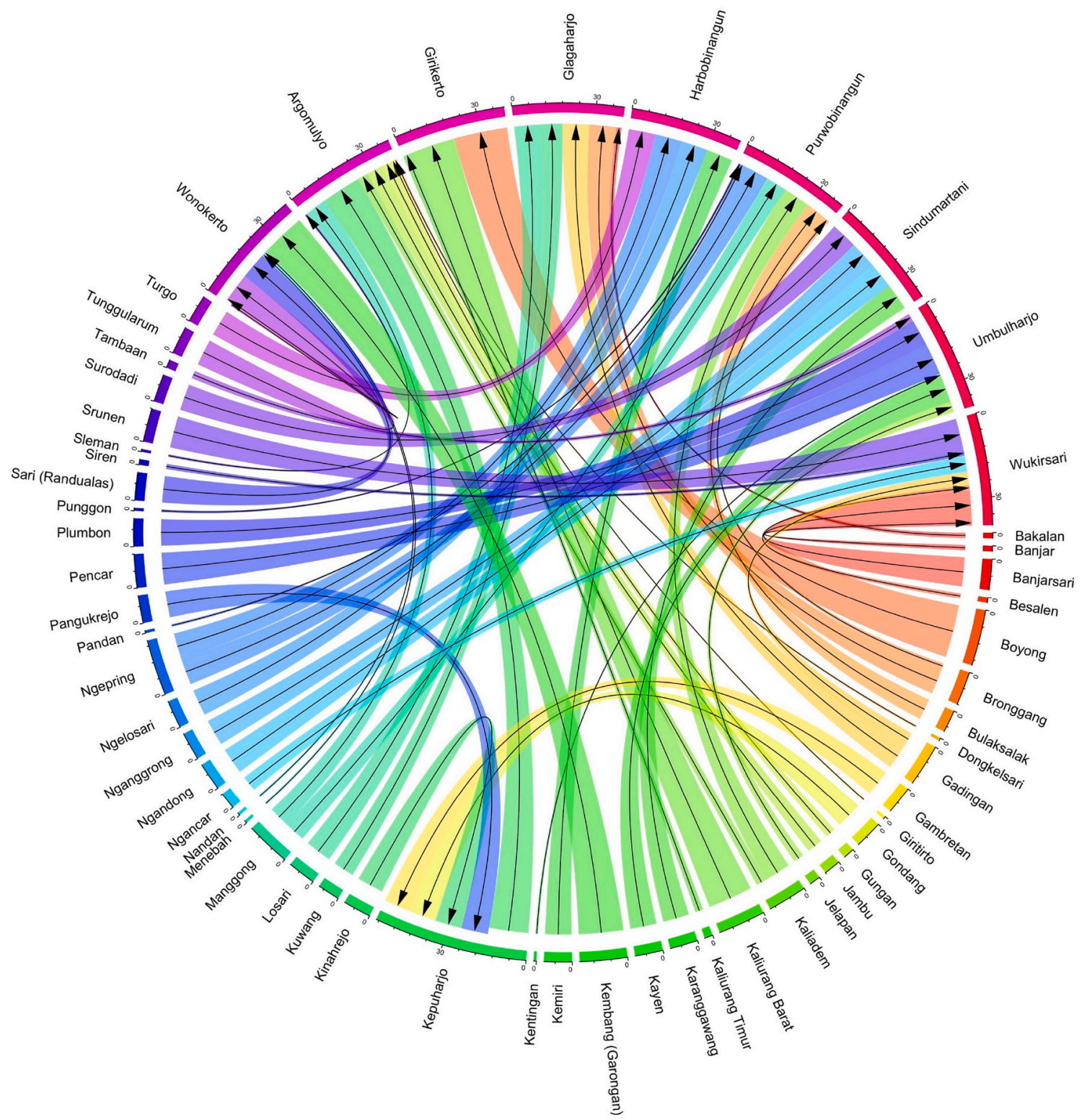

Fig. 3. Migrations Flows from Sending to Receiving Villages. The respondents in our survey came from 50 sending villages prior to the evacuation order that corresponded with the volcanic eruptions. The respondents were identified through our sampling procedure which first selected the 10 receiving villages.

\subsection{Sampling procedures}

Respondent sampling was conducted with two specific aims in mind. First, to create a sample that experienced varying levels of destruction. Second, to create a sample that included respondents who were still living in a disaster shelter, respondents who had moved home, and respondents who had moved on.

The Merapi eruptions struck five Regencies around the mountain: Boyolali, Klaten, Magelang, and Muntilan located within Central Java Province and Sleman Regency located within the Special Region of Yogyakarta (See Fig. 1). The damages caused by the disaster varied from one region to another. After taking into consideration time, costs, distance, and that this would be a pilot project on disaster mitigation, ten villages in Sleman Regency were chosen as the study location (See Fig. 2). Those ten villages are spread across 4 districts: Turi, Ngemplak, Cangkringan and Pakem.

The ten villages were selected based on the relative impact the Merapi eruptions had on each village, which ranged from those most severely affected to those only slightly affected. The villages classified as severely damages were Girikerto Villages (Turi District), Hargobinangun Village (Pakem District), Umbulharjo, Kepuharjo, Glagahharjo, Argomulyo Villages (Cangkringan District) and Sindumartani Village (Ngemplak District). The villages considered as slightly affected were Wonokerto Village (Turi District), Purwobinangun Village (Pakem District), and the village of Wukirsari (Cangkringan District).

\subsection{Respondent selection}

After establishing the sampling procedure, individual respondents were selected to obtain a sample of those who still lived in a shelter, those who had returned to their previous communities, and those who had moved away. The method for respondent selection was similar to the selection process used to identify villages and shelters within the districts. Residences were selected starting from the northernmost part of a village or shelter community and selection then moved from east to west and gradually south. Within this process, households were chosen randomly. The selection was conducted until there were 40 respondents from one village, with one respondent per household (respondents were 
individuals that identified as head of household). By drawing respondents from 10 different villages or shelter communities, we obtained a total respondent sample of 400 (two respondents were removed from the analytic sample because they were under the age of 18).

It is important to distinguish between the villages that respondents were sampled from and their villages or towns of origin (e.g., their "sending" village). The 398 respondents ultimately included in our analyses originated from 50 different villages or towns (See Fig. 3).

There is some overlap between the villages used for sampling and the villages of origin due to the fact that a portion of the sample had returned to their original village at the time of the survey, but many were still displaced or had moved on to new locations. The distribution of respondents from these various villages was such that roughly a third of the sending villages were represented by only one person. In contrast, many of the sending villages were represented by at least 10 respondents and several villages had 15-20.

The sample procedures and protocol for respondent selection were established with the goal of creating a sample representative of the varying levels of destruction that respondents experienced from the eruption. However, as a post-disaster study, we are unable to directly assess the extent to which our sample is representative of the predisaster population. Some of the persons displaced by the eruption may have migrated beyond the geographic scope of our study. While this is a concern, qualitative data gathered through interviews and focus groups suggest that the vast majority of displaced persons remained within the geographic region surrounding Mr. Merapi, a pattern consistent with research carried out by the Indonesian disaster management agency BNPB [8] and documented in related studies [9]. In addition, comparing demographic characteristics of our sample with 2010 census data for Indonesia [61] suggests that the distribution of respondents within our sample is comparable to that in the Special Region of Yogyakarta and similar to the general population of Indonesia (see Appendix A). For example, our study sample almost matches the population distribution of DI Yogyakarta in terms of religion and is comparable to that for Indonesia overall. While our study sample had a somewhat higher distribution of educational attainment in comparison to the population of DI Yogyakarta, this differences is likely attributable to the age distributions in our sample as educational attainment in DI Yogyakarta decreases with age, so a younger sample in our data would result in somewhat elevated percentages for education attainment.

\subsection{Measures}

The dependent variable in our analysis captured Migration Status in terms of whether or not a respondent and/or his/her household were displaced, in transition, had moved on, or had moved home at the time that the surveys were collected $(100 \%$ of our sample was originally displaced due to an evacuation order). The variable was constructed from responses to two questions in the survey: (1) Have they [the respondent] returned to their previous community since the disaster? (2) Do they [the respondent] currently live in temporary housing? (shelter, barrack, government relocation site, etc.)? Using responses to these questions, the following categories were constructed: (1) Moved Home - respondents who indicated that they had returned to their previous community and no longer living in temporary housing; (2) In Transition - respondents who indicated that they had returned to their previous community and were still living in temporary housing; (3) Displaced - respondents who indicated that they had yet to return to their previous community and were still living in temporary housing; (4) Moved On - respondents who indicated that they had yet to return to their previous community and no longer living in temporary housing. Moved Home was set as the reference category in order to analyze what types of recovery aid were associated with having moved home versus remaining displaced, but also to analyze what types of recovery aid were associated with having moved home versus having moved on. Additional analyses, conducted with "displaced" set as the comparison group, yielded similar results.

The independent variables of interest were divided into three sets. The first set included various types of recovery aid provided to households. Regarding Financial Recovery Aid, respondents were asked: "Did they or are they currently receiving any financial assistance from government and/or nongovernmental organizations (excluding family and friends)?" With respect to Food Recovery Aid, respondents were asked: "Did they or are they currently receiving food assistance from government and/or nongovernmental organizations (exclude family and friends)?" For Health Recovery Aid, respondents were asked: "Did they or are they currently receiving healthcare/medical assistance from government and or nongovernmental organizations (excluding family and friends)?" Finally, for Remittances, respondents were asked: "Does the household receive any money from people not living at their current residence?" to assess the impact of monetary aid provided to the respondent's household through their social network. Responses for all of the recovery aid questions were coded into dichotomous variables $(1=$ Ever Received). From these initial variables, three additional recovery aid variables were constructed. Economic Recovery Assistance combined Financial Recovery Aid with Remittances into a categorical variable coded ( 1 = None [reference category], $2=$ Both, $3=$ Remittances, $4=$ Financial Recovery Aid). Resource Recovery Assistance combined Food Recovery Aid with Health Recovery Aid into a categorical variable coded $(1=$ None [reference category], $2=$ Both, $3=$ Health Recovery Aid, $4=$ Food Recovery Aid). Household Recovery Assistance ${ }^{1}$ combined all 4 types of recovery aid into a categorical variable $(0=$ None, $1=1$ Type of Aid, $2=2$ Types of Aid, $3=3$ Types of Aid, and $4=4$ Types of Aid).

A second set included measures for demographic characteristics and place attachment, which often influence migration decisions [33, 62-64]. We measured Age as a categorical variable with six age groups ranging from $1=18-30$ years old to $6=70+$ years old (the first age group, 18 to 30 , was set as the reference category). Sex was included as a dichotomous variable with $1=$ Male. Married was also included as a dichotomous variable with $1=$ Married. Education was measured as a categorical variable with $1=$ Primary School or Less, $2=$ Junior High School, and 3 = Senior High School and Beyond (the first education group, Primary School or Less, was set as the reference category). Income was measured as a categorical variable with $1=0$ to 500,000 Rupiah; 2 $=50,001$ to 800,000 Rupiah; and $3=800,001$ to 1,000,000 Rupiah; and $4=1,000,000$ Rupiah and Beyond (the first income group, 0 to 500,000 Rupiah, was set as the reference category). Finally, as a proxy for community attachment, Residence Duration was calculated by dividing the total number of years lived in the previous community by the respondent's age and then dichotomizing the results such that $1=$ whole life, $0=$ other. We used this measure as prior research has indicated it is a strong predictor of community attachment [65].

The third set of independent variables included measures of the level of destruction experienced as a result of the volcano, which have been found to influence migration decisions in the context of disasters $[4,31$, 36,37 and were the basis upon which recovery aid was distributed in the aftermath of the Mt. Merapi eruptions. Residence Damaged or Destroyed was measured as a dichotomous variable with $1=$ Yes. Environmental Hazards measured the number of various environmental hazards the respondent's household had experienced in the past year, coded as a count variable ranging from one to three plus. The variable Perceived Destruction measured a respondent's perception of the total damage that they experienced because of the volcanic eruption, coded as a categorical variable with 1 = Low (reference group), $2=$ Medium, and

\footnotetext{
${ }^{1}$ Early iterations of the analysis evaluated a three category version of this variable wherein the final category was coded as " $3+$ " that had a larger number of respondents. The results for this version did not vary substantially or significantly from the 4 category version, and we opted to use the 4 category version to demonstrate the overall pattern, while recognizing that the 4th category was represented by a relatively small number of respondents $(n=24)$.
} 
Table 1

Descriptive statistics: Categorical variables.

\begin{tabular}{|c|c|c|c|c|c|}
\hline level & Moved Home & In Transition & Moved On & Displaced & Total \\
\hline \multicolumn{6}{|l|}{$\mathrm{n}$} \\
\hline & 190 & 24 & 22 & 162 & 398 \\
\hline \multicolumn{6}{|l|}{ Financial Recovery Aid (\%) } \\
\hline Not Received & $138(72.6)$ & $18(75.0)$ & $6(27.3)$ & $53(32.7)$ & $215(54.0)$ \\
\hline Received & $52(27.4)$ & $6(25.0)$ & $16(72.7)$ & $109(67.3)$ & $183(46.0)$ \\
\hline \multicolumn{6}{|l|}{ Health Recovery Aid (\%) } \\
\hline Not Received & $88(46.3)$ & $11(45.8)$ & $7(31.8)$ & $29(17.9)$ & $135(33.9)$ \\
\hline Received & $102(53.7)$ & $13(54.2)$ & $15(68.2)$ & $133(82.1)$ & $263(66.1)$ \\
\hline \multicolumn{6}{|l|}{ Food Recovery Aid (\%) } \\
\hline Not Received & $77(40.5)$ & $12(50.0)$ & $8(36.4)$ & $47(29.0)$ & $144(36.2)$ \\
\hline Received & $113(59.5)$ & $12(50.0)$ & $14(63.6)$ & $115(71.0)$ & $254(63.8)$ \\
\hline \multicolumn{6}{|l|}{ Remittances (\%) } \\
\hline Not Received & 159 (83.7) & $22(91.7)$ & $18(81.8)$ & $145(89.5)$ & $344(86.4)$ \\
\hline Received & $31(16.3)$ & $2(8.3)$ & $4(18.2)$ & $17(10.5)$ & $54(13.6)$ \\
\hline \multicolumn{6}{|l|}{ Economic Recovery Assistance (\%) } \\
\hline None & 119 (62.6) & $16(66.7)$ & $5(22.7)$ & $50(30.9)$ & $190(47.7)$ \\
\hline Both & $12(6.3)$ & $0(0.0)$ & $3(13.6)$ & $14(8.6)$ & $29(7.3)$ \\
\hline Remittances & $19(10.0)$ & $2(8.3)$ & $1(4.5)$ & $3(1.9)$ & $25(6.3)$ \\
\hline Financial Recovery Aid & $40(21.1)$ & $6(25.0)$ & $13(59.1)$ & $95(58.6)$ & $154(38.7)$ \\
\hline \multicolumn{6}{|l|}{ Resources Recovery Assistance (\%) } \\
\hline None & $57(30.0)$ & $8(33.3)$ & $4(18.2)$ & $25(15.4)$ & $94(23.6)$ \\
\hline Both & $82(43.2)$ & 9 (37.5) & $11(50.0)$ & $111(68.5)$ & $213(53.5)$ \\
\hline Health Recovery Aid & $20(10.5)$ & $4(16.7)$ & $4(18.2)$ & $22(13.6)$ & $50(12.6)$ \\
\hline Food Recovery Aid & $31(16.3)$ & $3(12.5)$ & $3(13.6)$ & $4(2.5)$ & $41(10.3)$ \\
\hline \multicolumn{6}{|l|}{ Household Recovery Assistance (\%) } \\
\hline 0 & $51(26.8)$ & $6(25.0)$ & $2(9.1)$ & $21(13.0)$ & $80(20.1)$ \\
\hline 1 & $35(18.4)$ & $5(20.8)$ & $4(18.2)$ & $17(10.5)$ & $61(15.3)$ \\
\hline 2 & $57(30.0)$ & $11(45.8)$ & $6(27.3)$ & $28(17.3)$ & $102(25.6)$ \\
\hline 3 & $39(20.5)$ & $2(8.3)$ & $7(31.8)$ & $83(51.2)$ & $131(32.9)$ \\
\hline 4 & $8(4.2)$ & $0(0.0)$ & 3 (13.6) & $13(8.0)$ & $24(6.0)$ \\
\hline \multicolumn{6}{|l|}{ Age (\%) } \\
\hline $18-30$ & $27(14.2)$ & 3 (12.5) & $7(31.8)$ & $26(16.0)$ & $63(15.8)$ \\
\hline $31-40$ & $42(22.1)$ & $1(4.2)$ & $6(27.3)$ & $42(25.9)$ & $91(22.9)$ \\
\hline $41-50$ & $46(24.2)$ & $8(33.3)$ & $6(27.3)$ & $30(18.5)$ & $90(22.6)$ \\
\hline $51-60$ & $48(25.3)$ & $5(20.8)$ & $1(4.5)$ & $37(22.8)$ & $91(22.9)$ \\
\hline $61-70$ & $19(10.0)$ & $5(20.8)$ & $1(4.5)$ & $20(12.3)$ & $45(11.3)$ \\
\hline $70+$ & $8(4.2)$ & $2(8.3)$ & $1(4.5)$ & $7(4.3)$ & $18(4.5)$ \\
\hline \multicolumn{6}{|l|}{ Sex $(\%)$} \\
\hline Female & $75(39.5)$ & $6(25.0)$ & $14(63.6)$ & $61(37.7)$ & $156(39.2)$ \\
\hline Male & $115(60.5)$ & $18(75.0)$ & $8(36.4)$ & $101(62.3)$ & $242(60.8)$ \\
\hline \multicolumn{6}{|l|}{ Married (\%) } \\
\hline No & $17(8.9)$ & $1(4.2)$ & $2(9.1)$ & $24(14.8)$ & $44(11.1)$ \\
\hline Yes & $173(91.1)$ & $23(95.8)$ & $20(90.9)$ & $138(85.2)$ & 354 (88.9) \\
\hline Education (\%) & & & & & \\
\hline Primary School or Less & $66(34.7)$ & 9 (37.5) & $7(31.8)$ & $55(34.0)$ & $137(34.4)$ \\
\hline Junior High School & 37 (19.5) & $7(29.2)$ & $6(27.3)$ & $57(35.2)$ & $107,926.9)$ \\
\hline Senior High School & $70(36.8)$ & $7(29.2)$ & $9(40.9)$ & $45(27.8)$ & $131(32.9)$ \\
\hline Beyond High School & $17(8.9)$ & $1(4.2)$ & $0(0.0)$ & $5(3.1)$ & $23(5.8)$ \\
\hline Income (\%) & & & & & \\
\hline $0-500,000$ & $50(26.3)$ & $6(25.0)$ & $5(22.7)$ & $48(29.6)$ & $109(27.4)$ \\
\hline $500,001-800,000$ & $57(30.0)$ & $5(20.8)$ & $2(9.1)$ & $44(27.2)$ & $108(27.1)$ \\
\hline $800,001-1,000,000$ & $35(18.4)$ & $9(37.5)$ & $3(13.6)$ & $43(26.5)$ & $90(22.6)$ \\
\hline $1,000,000+$ & $48(25.3)$ & $4(16.7)$ & $12(54.5)$ & $27(16.7)$ & $91(22.9)$ \\
\hline Residence Duration (\%) & & & & & \\
\hline Other & $81(42.6)$ & 9 (37.5) & $14(63.6)$ & $74(45.7)$ & $178(44.7)$ \\
\hline Whole Life & $109(57.4)$ & $15(62.5)$ & $8(36.4)$ & $88(54.3)$ & $220(55.3)$ \\
\hline Environmental Hazards (\%) & & & & & \\
\hline 1 & $80(42.1)$ & $11(45.8)$ & $6(27.3)$ & $49(30.2)$ & $146(36.7)$ \\
\hline 2 & $91(47.9)$ & $10(41.7)$ & $13(59.1)$ & $41(25.3)$ & $155(38.9)$ \\
\hline 3 & $19(10.0)$ & $3(12.5)$ & $3(13.6)$ & $72(44.4)$ & $97(24.4)$ \\
\hline Preceived Destruction (\%) & & & & & \\
\hline Low & $168(88.4)$ & $14(58.3)$ & $14(63.6)$ & $13(8.0)$ & $209(52.5)$ \\
\hline Medium & $15(7.9)$ & $8(33.3)$ & $5(22.7)$ & $20(12.3)$ & $48(12.1)$ \\
\hline High & $7(3.7)$ & $2(8.3)$ & $3(13.6)$ & $129(79.6)$ & $141(35.4)$ \\
\hline Strongly Fears Nature's Wrath (\%) & & & & & \\
\hline No & $59(31.1)$ & $7(29.2)$ & $5(22.7)$ & $55(34.0)$ & $126(31.7)$ \\
\hline Yes & $131(68.9)$ & $17(70.8)$ & $17(77.3)$ & $107(66.0)$ & $272(68.3)$ \\
\hline Residence Damaged (\%) & & & & & \\
\hline No & $150(78.9)$ & $14(58.3)$ & $13(59.1)$ & $16(9.9)$ & $193(48.5)$ \\
\hline Yes & $40(21.1)$ & $10(41.7)$ & $9(40.9)$ & $146(90.1)$ & 205 (51.5) \\
\hline
\end{tabular}


3 = High. Fears Nature's Wrath was coded as a dichotomous variable (1 $=$ Strongly Fears Nature's Wrath).

\section{Analytic strategy}

To address our research questions, we evaluated associations between respondents' migration status and various forms of recovery aid using multinomial logistic regression models. Given that $100 \%$ of the sample was displaced and only part of the sample subsequently received aid, these analyses were used in an attempt to identify the treatment effect of the various forms of recovery aid. The analyses were conducted in four stages.

In Stage One, each type of recovery aid was analyzed in isolation, with two separate models estimated for each type of aid. The first model adjusted for factors that are often associated with migration in nondisaster settings (i.e., respondent age, sex, education, income, and marital status). The second model adjusted for these factors as well as for factors that are often associated with migration in the context of disasters (e.g., perceptions of the severity of the disaster, whether or not a respondent's home was destroyed, whether or not they fear the wrath of nature, and community/place attachment). Only results for the fully adjusted models are presented. For Stage Two, all of the forms of recovery aid were included in one model-these estimates are thus adjusted for factors that are often associated with migration in non-disaster settings, factors that are often associated with migration in the context of disasters, and adjusted for other types of recover aid that a household may or may not have received. Stage Three grouped the different types of recovery aid into two categorical variables: economic recovery assistance and resource recovery assistance. Finally, Stage Four assessed the effect of "aid packages" in which households received varying amounts of recovery assistance packages.

Across the analyses, possible collinearity among independent variables was assessed using VIF values, all of which were below 2.5, which were deemed sufficiently low to not raise concern. Regression coefficients were converted to relative risk ratios and organized into data visualizations that included $95 \%$ confidence intervals using the $\mathrm{R}$ statistical programming environment [66].

\section{Results}

\subsection{Descriptive statistics}

The majority of respondents had either already moved home (48\%) or were still displaced (41\%) at the time of data collection (see Table 1 for descriptive statistics). In contrast, roughly $6 \%$ of respondents were still in transition and another roughly $6 \%$ had moved on or relocated to a new area. This distribution is consistent with the aforementioned tendency for individuals/households living near Mt. Merapi to return to their original communities after eruptions, despite awareness that Merapi is an active volcano that erupts regularly [7-10].

With regards to specific types of recovery aid, $46 \%$ reported receiving Financial Recovery Aid, 66\% reported receiving Health Recovery Aid, 64\% reported receiving Food Recovery Aid, and only 14\% reported receiving Remittances from their social networks. Concerning Economic Recovery Assistance, only 7\% of respondents reported receiving both Financial Recovery Aid and Remittances; 39\% reported receiving only Financial Recovery Aid; 6.3\% reported receiving only Remittances; and $48 \%$ reported receiving no Economic Recovery Assistance. In terms of Resource Recovery Assistance, 54\% of respondents reported receiving both Health Recovery Aid and Food Recovery Aid; 10\% reported receiving only Food Recovery Aid; 13\% reported receiving only Health Recovery Aid; and 24\% reported receiving no Resource Recovery Assistance. Regarding Household Recovery Assistance as "aid packages," only 6\% of respondents reported receiving all 4 types of recovery assistance; $33 \%$ reported receiving 3 types of recovery assistance; $26 \%$ received 2 types of recovery assistance; $15 \%$ received only 1 types of recovery assistance;
Table 2

Summary of relative risk ratios from multinomial logistic regression models as core results for migration status analyses.

\begin{tabular}{|c|c|c|c|}
\hline & \multicolumn{3}{|c|}{ Dependent variable: Migration Status } \\
\hline & $\begin{array}{l}\text { In Transition } \\
\text { (1) }\end{array}$ & $\begin{array}{l}\text { Moved On } \\
\text { (2) }\end{array}$ & $\begin{array}{l}\text { Displaced } \\
\text { (3) }\end{array}$ \\
\hline \multicolumn{4}{|l|}{ Stage 1: Aid Specific Analyses } \\
\hline Financial Recovery Aid & $0.59(0.59)$ & $\begin{array}{l}11.62^{* * *} \\
(0.62)\end{array}$ & $\begin{array}{l}5.09 * * * \\
(0.43)\end{array}$ \\
\hline Food Recovery Aid & $0.70(0.48)$ & $1.58(0.52)$ & $1.68(0.42)$ \\
\hline Health Recovery Aid & $0.86(0.51)$ & $2.45(0.57)$ & $\begin{array}{l}4.16^{* *} \\
(0.49)\end{array}$ \\
\hline \multicolumn{4}{|l|}{ Stage 2: Aid Adjusted Analyses } \\
\hline Financial Recovery Aid & $0.64(0.63)$ & $\begin{array}{l}15.27^{* * * *} \\
(0.69)\end{array}$ & $\begin{array}{l}5.03^{* * *} \\
(0.49)\end{array}$ \\
\hline Food Recovery Aid & $0.73(0.59)$ & $0.38(0.68)$ & $0.48(0.54)$ \\
\hline Health Recovery Aid & $1.14(0.60)$ & $2.93(0.72)$ & $4.16 *(0.57)$ \\
\hline $\begin{array}{l}\text { Remittances } \\
\text { Stage 3: Grouped Aid Analyses }\end{array}$ & \multicolumn{2}{|c|}{ Stage 3: Grouped Aid Analyses } & $0.60(0.63)$ \\
\hline $\begin{array}{l}\text { Economic Recovery Assistance: } \\
\text { Both }\end{array}$ & $\begin{array}{l}0.00 * * * \\
(0.0000)\end{array}$ & $\begin{array}{l}17.91^{* *} \\
(1.00)\end{array}$ & $4.34(0.84)$ \\
\hline $\begin{array}{l}\text { Economic Recovery Assistance: } \\
\text { Remittances }\end{array}$ & $0.60(0.90)$ & $1.32(1.27)$ & $0.38(1.08)$ \\
\hline $\begin{array}{l}\text { Economic Recovery Assistance: } \\
\text { Financial Aid }\end{array}$ & $0.68(0.60)$ & $\begin{array}{l}11.72^{* * *} \\
(0.68)\end{array}$ & $\begin{array}{l}4.65 * * * \\
(0.46)\end{array}$ \\
\hline $\begin{array}{l}\text { Resource Recovery Assistance: } \\
\text { Both }\end{array}$ & $0.69(0.58)$ & $2.81(0.69)$ & $3.49 *(0.55)$ \\
\hline $\begin{array}{l}\text { Resource Recovery Assistance: } \\
\text { Health Aid }\end{array}$ & $0.87(0.80)$ & $3.13(0.89)$ & $3.36(0.73)$ \\
\hline $\begin{array}{l}\text { Resource Recovery Assistance: } \\
\text { Food Aid }\end{array}$ & $0.56(0.89)$ & $1.60(0.92)$ & $0.46(1.00)$ \\
\hline \multicolumn{4}{|l|}{ Stage 4: Aid Packages Analyses } \\
\hline $\begin{array}{l}\text { Household Recovery Assistance: } \\
1\end{array}$ & $1.54(0.74)$ & $3.20(1.03)$ & $2.87(0.74)$ \\
\hline $\begin{array}{l}\text { Household Recovery Assistance: } \\
\quad 2\end{array}$ & $1.36(0.64)$ & $3.01(0.93)$ & $1.50(0.66)$ \\
\hline $\begin{array}{l}\text { Household Recovery Assistance: } \\
\quad 3\end{array}$ & $0.27(0.97)$ & $8.14 *(0.96)$ & $\begin{array}{l}6.33^{* *} \\
(0.64)\end{array}$ \\
\hline $\begin{array}{l}\text { Household Recovery Assistance: } \\
4\end{array}$ & $\begin{array}{l}0.00^{* * *} \\
(0.0000)\end{array}$ & $\begin{array}{l}34.96 * * \\
(1.25)\end{array}$ & $\begin{array}{l}10.61^{*} \\
(1.02)\end{array}$ \\
\hline
\end{tabular}

Note: $: \mathrm{p}<0.05 ; *: \mathrm{p}<0.01 ; * * * \mathrm{p}<0.001$.

and $20 \%$ received none whatsoever.

\subsection{Stage 1: aid specific analyses}

A summary of core results for analyses evaluating the relationship between Migration Status and the various types of recovery aid are presented as Relative Risk Ratios (RRR) in Table 2 and presented visually with 95\% confidence intervals in Figs. 4-6. Tables containing complete information for all analyses are presented in Appendix B.

Recovery aid was distributed by government and non-government organizations to households in the form of financial aid as well as "in kind" resources such as food and health aid. After adjusting for factors typically associated with migration under non-disaster circumstances as well as in the context of disasters (Stage 1), respondents whose household received Financial Recovery Aid were more likely to have Moved On (RRR $=11.62 ; \mathrm{p}<0.001)$, compared to having Moved Home. Financial Recovery Aid was the only type of recovery aid in Stage 1 that resulted in an association that was both positive and statistically significant with regards to respondents who reported that they had moved on. Respondents whose household received Food Recovery Aid were more likely to have Moved On (RRR = 1.58), compared to having Moved Home. Likewise, respondents whose household received Health Recovery Aid were more likely to have Moved On $(\mathrm{RRR}=2.45)$ compared to having Moved Home. However, the results for food and health aid were not statistically significant. In addition to recovery aid received from government and non-government organizations, some households reported that they received remittances from their social network. Respondents whose household received Remittances were more likely to have Moved 


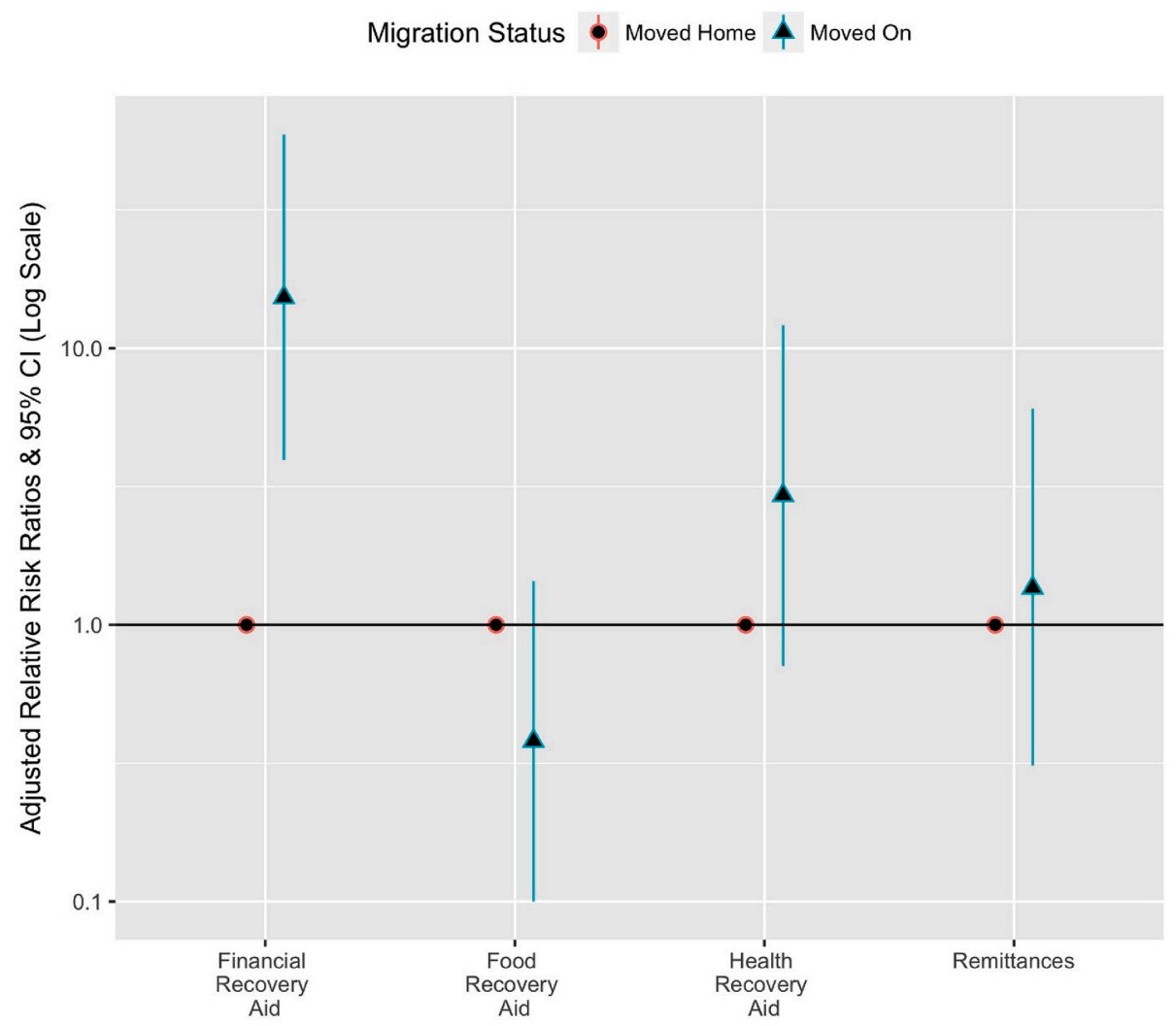

Fig. 4. Aid Specific Relative Risk Ratios for Migration Status. Financial Recovery Aid clearly has a strong, positive association with the migration status of having moved on. While still demonstrating positive associations, no other type of recovery aid is statistically significant with regards to the migration status of having moved on.

On $(\mathrm{RRR}=1.74)$, compared to having Moved Home. However, these results were not statistically significant.

\subsection{Stage 2: aid adjusted analyses}

After adjusting for other types of recovery aid in addition to other control variables, the association between respondents whose household received Financial Recovery Aid and having Moved On increased in strength (RRR $=15.27 ; \mathrm{p}<0.001$ ). This association as well as the associations between other types of recovery aid are visualized in Fig. 4, which clearly indicates that after adjusting for the other types of recovery aid, Financial Recovery Aid was the only type of recovery aid that resulted in an association that was both positive and statistically significant with regards to respondents who reported that they had moved on.

\subsection{Stage 3: grouped aid analyses}

In the grouped analyses, respondents whose household received the combination of both types of Economic Recovery Assistance were more likely to have Moved On ( $R R R=17.91 ; \mathrm{p}<0.01)$, compared to having Moved Home. Similarly, respondents whose household received only Financial Recovery Aid were more likely to have Moved On $(\mathrm{RRR}=11.72$; $\mathrm{p}<0.001$ ), compared to having Moved Home. As Fig. 5 clearly indicates, both of these results were statistically significant. However, while respondents whose household only received Remittances were still more likely to have Moved On (RRR = 1.32), compared to having Moved Home, these results were not statistically significant. Respondents whose household received the combination of both types of Resource Recovery Assistance were more likely to have Moved On (RRR $=2.81$ ), compared to having Moved Home. As before, respondents whose household received only Food Recovery Aid or Health Recovery Aid were more likely to have Moved On, compared to having Moved Home. However, as before, these results were not statistically significant.

\subsection{Stage 4: aid packages analyses}

Ultimately, the extent to which households received recovery aid varied substantially; i.e., 80 respondents indicated that their household had received no recovery aid whatsoever, 61 respondents indicated that their household received only 1 type of aid, 102 respondents indicated that their household received 2 types of aid, 131 respondents indicated that their household received 3 types of aid, and 24 respondents indicated that their household had received every type of aid. In terms of these "aid packages", after adjusting for other factors, respondents whose household received every type of aid, compared to those whose household received none, were the most likely to have Moved On (RRR $=34.96 ; \mathrm{p}<0.01$ ), compared to having Moved Home. Similarly, respondents whose household received 3 types of aid, compared to those whose household received none, were more likely to have Moved On $(\mathrm{RRR}=8.14 ; \mathrm{p}<0.05)$ compared to having Moved Home (see also Fig. 6).

\section{Discussion}

Our objective in this study was to explore the extent to which recovery aid in the aftermath of a disaster may influence Migration Status. As such, we note several issues requiring further investigation and policy consideration. However, before discussing these considerations, we stress that there is need for caution in interpreting these results-they are associations and our ability to make causal inference is limited. Our interpretation that these associations suggest possible treatment effects is based primarily upon the temporal sequence of events. However, these limitations acknowledged, we anticipate that these preliminary findings have policy implications for government and non-government 


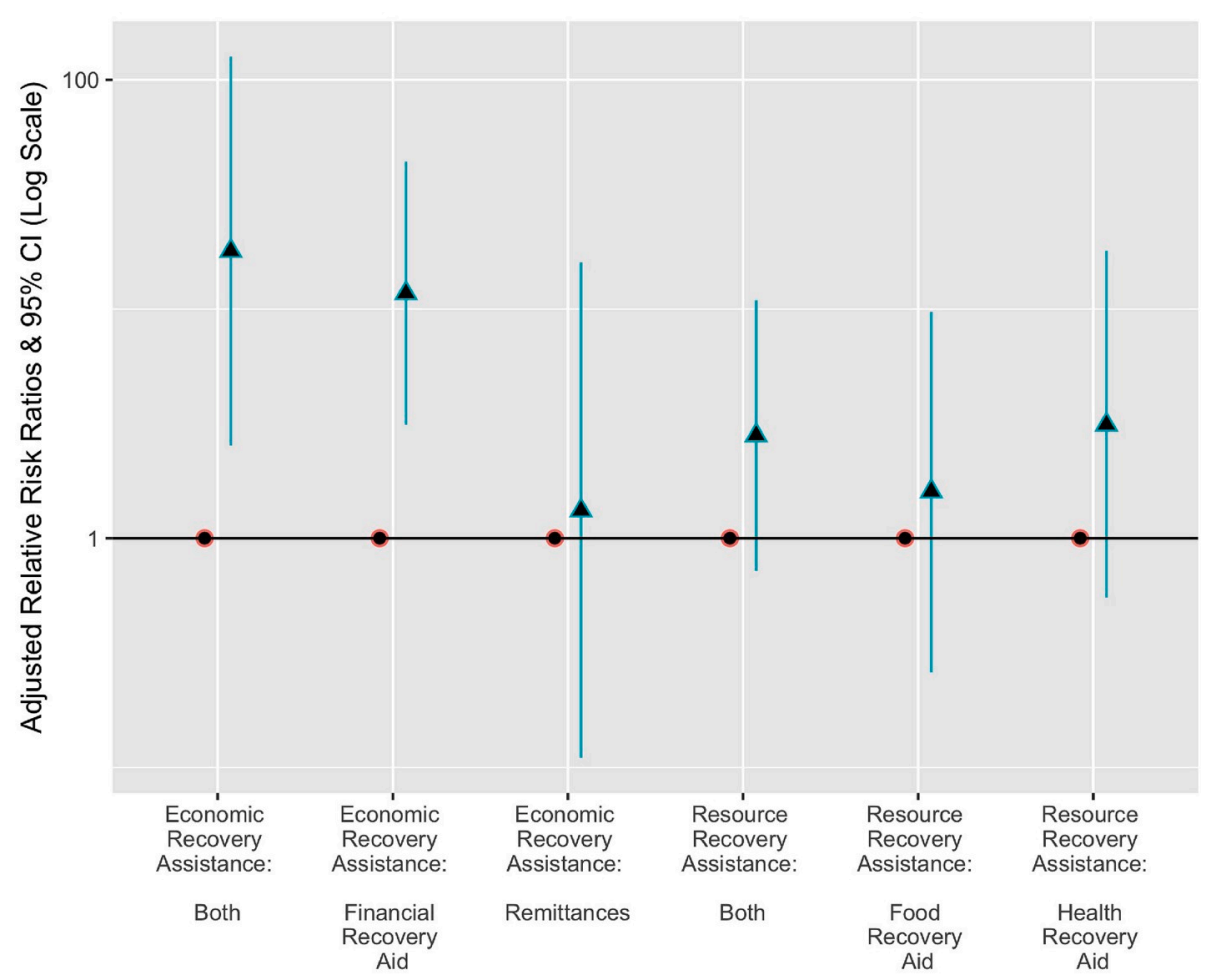

Fig. 5. Grouped Aid Relative Risk Ratios for Migration Status. Economic Recovery Aid: Both and Economic Recovery Aid: Financial Recovery Aid clearly have strong, positive associations with the migration status of having moved on. While still demonstrating positive associations, no other combination of recovery aid is statistically significant with regards to the migration status of having moved on.

organizations seeking to influence how populations resettle in the aftermath of a disaster-especially for organizations operating to reduce risks in the Merapi area. Furthermore, these preliminary findings can help guide future research; particularly research focused on the welldocumented risks and reoccurring impacts of eruptions form Mt. Merapi.

With respect to the broad exploration of the extent to which recovery aid in the aftermath of a disaster may influence Migration Status, all of the different types of recovery aid analyzed were positively associated with respondents reporting that their household had moved on compared to moved home, which is consistent with the first of our hypotheses. However, of the different types of recovery aid analyzed, only Financial Recovery Aid was both associated strongly with having moved on and statistically significant when analyzed by itself (consistent with our second hypothesis). Moreover, the strength of this association increased after adjusting for whether or not a household had received other types of recovery aid. The grouped analyses add some nuance to the aid specific results by demonstrating that the combination of Financial Recovery Aid with Remittances resulted in an association with having moved on that was even stronger when both types of aid were received as opposed to when just Financial Recovery Aid was received. The caveat for future researchers and policy makers is that while the combined effect was stronger, the difference was not statistically significant (the confidence intervals overlapped). This nuance was extended in the "aid packages" analyses wherein the results suggest that the "aid packages" that were relatively more effective were those that included most, if not all, of the different types of recovery aid, a finding that is consistent with our third and final hypothesis. This suggests that while food and health recovery aid as well as remittances may not have been sufficient in and of themselves to increase resettlement, they may enhance the effect of financial recovery aid. Given the interest to facilitate household relocation to safer areas as a means of risk reduction in the region $[8,9]$, these results suggest that the provision of financial assistance is likely the best type of recovery aid for achieving this objective. However, policy makers should consider that it is possible that providing financial assistance in combination with other recovery resources may yield even stronger incentives for resettlement overall.

While we believe this study has policy implications and also contributes to the literature on migration in the aftermath of a disaster, we recognize that it is not without limitation. The data used were part of a pilot study organized to document in detail the experiences of victims of the disaster. This affects our ability to leverage these data for statistical analyses investigating migration status as this was not the main purpose of the data. In addition, as a pilot study, only a relatively small sample of data was collected. This limits the statistical power of our analyses such that some indicators may have had stronger statistical significance (as well as tighter confidence intervals) if the study size was larger. Likewise, more nuanced analyses could have been conducted; e.g., a full categorical breakdown of different aid package combinations rather than a count of the various categories.

There is also the potential for bias within our data, as discussed in detail in the methods section. Sample bias may exist as our sample only included the geographic region surrounding Mt. Merapi. It is possible that some of the persons displaced by the eruption migrated beyond the geographic scope of our study. It is unfortunate that for individuals or households who may have moved further away, we are unable to assess whether or not they were more likely to have experienced more severe consequences of the disaster compared to those who remained in the same geographic region or if they were they more likely to have had the means to resettle further from their original home. It is difficult to directly assess how this potential bias may affect our results, but given our theoretical framework we anticipate that their absence from the study results in more conservative estimates. It is possible that there is also recall bias within our data due to the timing of data collection. However, given that data collection for all respondents occurred in the 


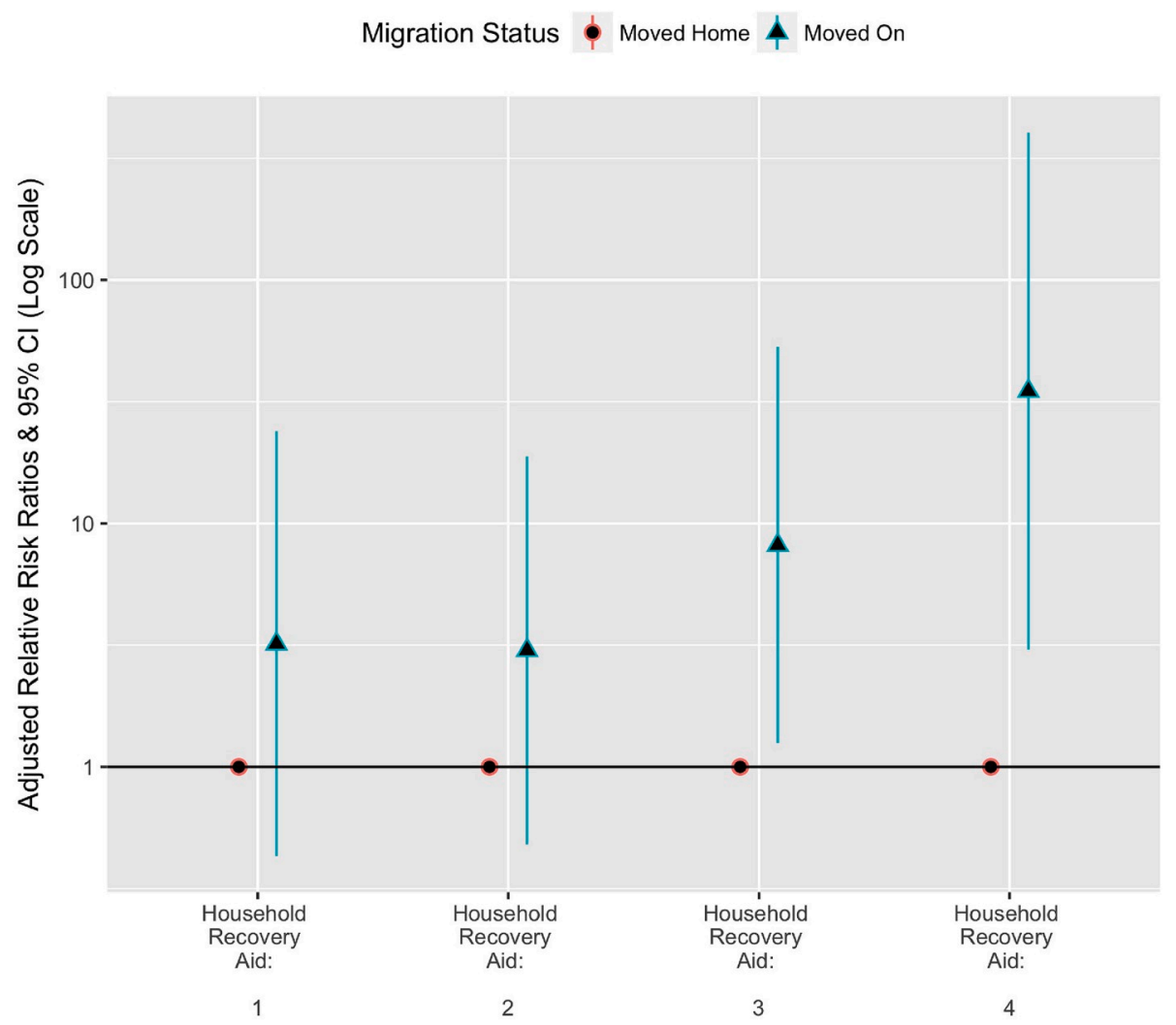

Fig. 6. Aid Packages Relative Risk Ratios for Migration Status. Household Recovery Aid: 4 and Household Recovery Aid: 3 clearly have strong, positive associations with the migration status of having moved on. No other combination of recovery aid is statistically significant with regards to the migration status of having moved on.

same time period, we anticipate that any recall bias within our data is non-differential.

Finally, as with the majority of disasters from natural hazards, these findings come from a specific event, occurring at a specific time and in a specific location. This is important given that the destruction resulting from Mt. Merapi's eruption only became a "natural disaster" through interaction with local social systems. As Perry states, "It is not the hurricane wind or storm surge that makes the disaster; these are the sources of the damage. The disaster is the impact on individual coping patterns and the inputs and outputs of social systems" [67]; 12). In as much as a disaster is a social phenomenon $[67,68]$ that is inherently local, it is difficult to gauge the extent to which our findings are generalizable beyond the context of Java, Indonesia. At a minimum, these findings could inform other research studies through incorporation into a future systematic review or meta analysis of indicators of return migration in the aftermath of disasters from natural hazards.

Despite these limitations, we have endeavored to provide meaningful insights to potential associations between various types of recovery aid and migration status in the aftermath of a disaster. Moreover, as we move beyond this pilot study to continue conducting research in the region, these results, as well as lessons learned while conducting this pilot study, will inform our efforts to better understand the social ramifications of Mt. Merapi's frequent eruptions-the most recent of which occurred earlier this year [69].

\section{Conclusion}

Despite the well-known danger, the area surrounding the mountain remains densely populated and the site of frequent return migrations as households persist in returning to their original communities once the dangers associated with an eruption have subsided [7-10]. Our overall results are consistent with this documented trend. This pattern of return migration is so prominent that the Indonesian government has endeavored to create incentives to encourage resettlement to areas that are less hazardous, but still in the general Mt. Merapi area. This pattern is perhaps somewhat unique, as it is in contrast to findings from research studies from other geographic areas and context that found that post disaster, more educated people tended to move to cities in their same region, which resulted in a secondary disaster in the form of brain drain. This migration pattern could be due to the limited types of jobs in local areas post-disaster and need to diversify family income [70].

This study evaluated multiple types of recovery aid in order to identify which types may play a role in influencing migration decisions in the aftermath of a disaster. While return migration in these circumstances may constitute an opportunity for migrants to reclaim what they lost and begin anew, classic studies on the effects of disasters from natural hazards suggest that the process of starting over is difficult and life is never truly the same [34,71]. The trip home is but the first step in regaining what was lost, and therefore, return may not be the best choice. Moreover, there is apparent interest in the current context to help the most vulnerable relocate to safer locations. Given these circumstances, future research should evaluate the effects of return migration on life outcomes, such as health and quality of life. While buildings can be rebuilt, the same is not always true of the past [71], and perhaps for some it would indeed be better to move on rather than move back-especially in a world where disasters from natural hazards are an ever more frequent reality.

\section{Ethical standards}

This study met the criteria for exemption from human subjects IRB review at Brigham Young University. The authors had no financial or personal relationships with other people or organizations that could have inappropriately influenced this study. This research was funded in 
part by a grant from the Brigham Young University College of Family, Home, and Social Sciences as well as in part from a Brigham Young University Mentoring Environment Grant.

\section{Acknowledgements}

The original pilot study was organized and lead by Dr. Ralph B.
Brown. Sadly, after a heroic battle with pancreatic cancer, Ralph passed away in 2014 , long before this paper was prepared for publication. We are indebted to Ralph as the principle investigator of the pilot study, but even more so as our dear colleague, friend, and mentor. You are greatly missed, hoser! We are also grateful for the contributions of Rilee Buttars and Alex Currit to the data gathering process and to the many research assistants who worked with us in the field.

\section{Appendix A}

Table 3

Statistics for Comparing Sample to General Population

\begin{tabular}{llll}
\hline & $\begin{array}{l}\text { Study Sample } \\
\%\end{array}$ & $\begin{array}{l}\text { Special Region of Yogyakarta } \\
\%\end{array}$ & $\begin{array}{l}\text { Indonesia } \\
\%\end{array}$ \\
\hline $\begin{array}{l}\text { Demographic Characteristics: } \\
\text { Marital Status }\end{array}$ & & & 31.9 \\
Single & 3.5 & 32.6 & 60.5 \\
Married & 89.0 & 59.0 & 1.8 \\
Divorced & 2.0 & 1.4 & 5.5 \\
Widowed & 5.5 & 6.8 & 87.2 \\
Religion & & & 9.8 \\
Islam & 92.2 & 92.0 & 3.0 \\
Christian & 7.5 & 0.5 & 21.8 \\
Other & 0.3 & & 28.5 \\
Education Attainment & & 10.0 & 20.2 \\
None & 5.0 & 36.5 & 29.5 \\
Some Primary & 29.6 & 16.5 & \\
Lower Secondary & 26.7 & 37.0 & \\
Upper Secondary and Beyond & 38.7 & & \\
\hline
\end{tabular}

Comparison data obtained from Indonesia's 2010 census [61], The marital status of the study sample is comparable to percentages reported for DI Yogyakarta and Indonesia overall in terms of divorced and widowed. The higher proportion of married compared to single is likely attributable to respondent status as head of household. In terms of religion, our study sample almost matches the population distribution DI Yogyakarta and is comparable to that for Indonesia overall. Our study sample has a somewhat higher distribution of educational attainment in comparison to the population of DI Yogyakarta, an areas that is known for having higher education attainment compared to national averages [29]. This differences is likely attributable to the age distributions in our sample as educational attainment in DI Yogyakarta decreases with age, so a younger sample in our data would result in somewhat elevated percentages for education attainment.

Note: Columns may not sum to $100 \%$ due to rounding.

\section{Appendix B}

Table 4

Multinomial Logistic Regression Results for Migration Status and Financial Recovery Aid

\begin{tabular}{|c|c|c|c|}
\hline & \multicolumn{3}{|l|}{ Dependent variable: } \\
\hline & $\begin{array}{l}\text { Predicting Migration Status } \\
\text { (1) }\end{array}$ & $\begin{array}{l}\text { Moved On } \\
\text { (2) }\end{array}$ & $\begin{array}{l}\text { Displaced } \\
(3)\end{array}$ \\
\hline Financial Recovery Aid & $0.59(0.59)$ & $11.62^{* * *}(0.62)$ & $5.09 * * *(0.43)$ \\
\hline Age: $31-40$ & $0.20(1.22)$ & $0.63(0.75)$ & $0.95(0.67)$ \\
\hline Age: $41-50$ & $1.03(0.81)$ & $0.34(0.74)$ & $0.86(0.67)$ \\
\hline Age: $51-60$ & $0.64(0.85)$ & $0.04 * *(1.22)$ & $0.57(0.70)$ \\
\hline Age: $61-70$ & $1.34(0.89)$ & $0.23(1.25)$ & $0.73(0.78)$ \\
\hline Age: $70+$ & $1.92(1.14)$ & $0.41(1.35)$ & $0.27(1.05)$ \\
\hline Sex (Male) & $1.85(0.69)$ & $0.74(0.82)$ & $1.85(0.57)$ \\
\hline Marital Status (Married) & $3.84(1.20)$ & $0.47(0.98)$ & $0.47(0.61)$ \\
\hline Junior High School & $1.48(0.65)$ & $0.90(0.83)$ & $1.06(0.56)$ \\
\hline Senior High School + & $0.64(0.63)$ & $0.37(0.70)$ & $0.43(0.53)$ \\
\hline Income: 500,001-800,000 RP & $1.01(0.71)$ & $0.33(0.96)$ & $0.77(0.57)$ \\
\hline Income: $800,001-1,000,000 \mathrm{RP}$ & $2.25(0.65)$ & $0.82(0.86)$ & $1.08(0.58)$ \\
\hline Income: $1,000,000+\mathrm{RP}$ & $0.81(0.74)$ & $4.89 *(0.72)$ & $0.75(0.61)$ \\
\hline Residence Duration & $0.90(0.60)$ & $0.44(0.82)$ & $0.37(0.55)$ \\
\hline Environmental Hazards & $0.68(0.37)$ & $0.97(0.41)$ & $1.12(0.28)$ \\
\hline Medium Destruction & $8.30 * *(0.73)$ & $2.37(0.77)$ & $5.73^{* *}(0.57)$ \\
\hline High Destruction & $3.32(1.03)$ & $4.44(0.97)$ & $110.37 * * *(0.63)$ \\
\hline Fears Nature's Wrath & $0.82(0.55)$ & $3.41(0.66)$ & $1.63(0.46)$ \\
\hline Residence Damaged & $1.26(0.63)$ & $1.29(0.67)$ & $3.98 * *(0.50)$ \\
\hline Constant & $0.04 *(1.53)$ & $0.10(1.40)$ & $0.07 * *(1.01)$ \\
\hline Akaike Inf. Crit & 541.88 & 541.88 & 541.88 \\
\hline
\end{tabular}


Note: $* \mathrm{p}<0.05 ; * * \mathrm{p}<0.01 ; * * * \mathrm{p}<0.001$

Table 5

Multinomial Logistic Regression Results for Migration Status and Health Recovery Aid

\begin{tabular}{|c|c|c|c|}
\hline & \multicolumn{3}{|c|}{ Dependent variable: Migration Status } \\
\hline & $\begin{array}{l}\text { In Transition } \\
\text { (1) }\end{array}$ & $\begin{array}{l}\text { Moved On } \\
\text { (2) }\end{array}$ & $\begin{array}{l}\text { Displaced } \\
\text { (3) }\end{array}$ \\
\hline Health Recovery Aid & $0.86(0.51)$ & $2.45(0.57)$ & $4.16^{* *}(0.49)$ \\
\hline Age: $31-40$ & $0.21(1.22)$ & $0.51(0.70)$ & $0.87(0.65)$ \\
\hline Age: $41-50$ & $1.24(0.78)$ & $0.35(0.71)$ & $0.86(0.66)$ \\
\hline Age: $51-60$ & $0.69(0.85)$ & $0.05 *(1.19)$ & $0.62(0.69)$ \\
\hline Age: $61-70$ & $1.57(0.88)$ & $0.21(1.22)$ & $0.86(0.75)$ \\
\hline Age: $70+$ & $2.00(1.16)$ & $0.38(1.37)$ & $0.26(1.10)$ \\
\hline Sex (Male) & $1.89(0.70)$ & $0.55(0.76)$ & $1.59(0.55)$ \\
\hline Marital Status (Married) & $3.68(1.18)$ & $0.63(0.93)$ & $0.45(0.61)$ \\
\hline Junior High School & $1.38(0.64)$ & $1.68(0.76)$ & $1.73(0.53)$ \\
\hline Senior High School + & $0.60(0.62)$ & $0.63(0.64)$ & $0.69(0.51)$ \\
\hline Income: 500,001-800,000 RP & $0.89(0.69)$ & $0.26(0.95)$ & $0.81(0.54)$ \\
\hline Income: $800,001-1,000,000 \mathrm{RP}$ & $2.01(0.65)$ & $0.80(0.82)$ & $1.19(0.57)$ \\
\hline Income: $1,000,000+\mathrm{RP}$ & $0.76(0.74)$ & $4.23 *(0.66)$ & $0.76(0.59)$ \\
\hline Residence Duration & $0.83(0.60)$ & $0.56(0.72)$ & $0.43(0.52)$ \\
\hline Environmental Hazards & $0.71(0.36)$ & $1.05(0.37)$ & $1.15(0.28)$ \\
\hline Medium Destruction & $7.65^{* *}(0.69)$ & $3.01(0.74)$ & $6.93^{* * *}(0.57)$ \\
\hline High Destruction & $3.89(0.99)$ & $4.87(0.93)$ & $127.05^{* * *}(0.61)$ \\
\hline Fears Nature's Wrath & $0.94(0.53)$ & $2.19(0.61)$ & $1.43(0.45)$ \\
\hline Residence Damaged & $1.19(0.62)$ & $1.46(0.63)$ & $3.75^{* *}(0.49)$ \\
\hline Constant & $0.04 *(1.53)$ & $0.14(1.33)$ & $0.04 * *(1.07)$ \\
\hline Akaike Inf. Crit & 562.43 & 562.43 & 562.43 \\
\hline
\end{tabular}

Note:* $\mathrm{p}<0.05 ;{ }^{* *} \mathrm{p}<0.01 ;{ }^{* * *} \mathrm{p}<0.001$.

Table 6

Multinomial Logistic Regression Results for Migration Status and Food Recovery Aid

\begin{tabular}{|c|c|c|c|}
\hline & \multicolumn{3}{|c|}{ Dependent variable: Migration Status } \\
\hline & $\begin{array}{l}\text { In Transition } \\
\text { (1) }\end{array}$ & $\begin{array}{l}\text { Moved On } \\
\text { (2) }\end{array}$ & $\begin{array}{l}\text { Displaced } \\
\text { (3) }\end{array}$ \\
\hline Food Recovery Aid & $0.70(0.48)$ & $1.58(0.52)$ & $1.68(0.42)$ \\
\hline Age: $31-40$ & $0.22(1.21)$ & $0.46(0.70)$ & $0.75(0.63)$ \\
\hline Age: $41-50$ & $1.26(0.78)$ & $0.34(0.70)$ & $0.74(0.65)$ \\
\hline Age: $51-60$ & $0.77(0.84)$ & $0.05 *(1.18)$ & $0.52(0.68)$ \\
\hline Age: $61-70$ & $1.47(0.88)$ & $0.19(1.21)$ & $0.70(0.75)$ \\
\hline Age: $70+$ & $2.07(1.14)$ & $0.28(1.32)$ & $0.20(1.06)$ \\
\hline Sex (Male) & $1.88(0.68)$ & $0.66(0.76)$ & $1.82(0.55)$ \\
\hline Marital Status (Married) & $3.39(1.18)$ & $0.69(0.92)$ & $0.56(0.59)$ \\
\hline Junior High School & $1.43(0.65)$ & $1.42(0.75)$ & $1.41(0.53)$ \\
\hline Senior High School + & $0.63(0.61)$ & $0.56(0.64)$ & $0.56(0.50)$ \\
\hline Income: $500,001-800,000 \mathrm{RP}$ & $0.85(0.69)$ & $0.27(0.95)$ & $0.78(0.54)$ \\
\hline Income: $800,001-1,000,000 \mathrm{RP}$ & $2.05(0.64)$ & $0.70(0.82)$ & $1.01(0.55)$ \\
\hline Income: $1,000,000+\mathrm{RP}$ & $0.72(0.74)$ & $3.90 *(0.64)$ & $0.71(0.58)$ \\
\hline Residence Duration & $0.82(0.59)$ & $0.55(0.73)$ & $0.42(0.52)$ \\
\hline Environmental Hazards & $0.72(0.36)$ & $1.05(0.37)$ & $1.16(0.27)$ \\
\hline Medium Destruction & $7.08 * *(0.69)$ & $3.06(0.74)$ & $7.30 * * *(0.56)$ \\
\hline High Destruction & $3.83(1.00)$ & $4.60(0.91)$ & $109.92^{* * *}(0.58)$ \\
\hline Fears Nature's Wrath & $0.96(0.52)$ & $2.19(0.62)$ & $1.32(0.44)$ \\
\hline Residence Damaged & $1.21(0.62)$ & $1.69(0.62)$ & $4.44 * *(0.48)$ \\
\hline Constant & $0.04 *(1.54)$ & $0.17(1.31)$ & $0.08 *(0.99)$ \\
\hline Akaike Inf. Crit & 570.82 & 570.82 & 570.82 \\
\hline
\end{tabular}

Table 7

Multinomial Logistic Regression Results for Migration Status and Remittances

\begin{tabular}{|c|c|c|c|}
\hline & \multicolumn{3}{|c|}{ Dependent variable: Migration Status } \\
\hline & $\begin{array}{l}\text { In Transition } \\
\text { (1) }\end{array}$ & $\begin{array}{l}\text { Moved On } \\
\text { (2) }\end{array}$ & $\begin{array}{l}\text { Displaced } \\
\text { (3) }\end{array}$ \\
\hline Remittances & $0.38(0.85)$ & $1.74(0.69)$ & $0.87(0.59)$ \\
\hline Age: $31-40$ & $0.19(1.22)$ & $0.52(0.72)$ & $0.75(0.64)$ \\
\hline Age: $41-50$ & $1.21(0.78)$ & $0.36(0.70)$ & $0.72(0.64)$ \\
\hline Age: $51-60$ & $0.72(0.84)$ & $0.05^{*}(1.18)$ & $0.53(0.67)$ \\
\hline Age: $61-70$ & $1.34(0.88)$ & $0.19(1.22)$ & $0.64(0.74)$ \\
\hline Age: $70+$ & $1.99(1.13)$ & $0.27(1.34)$ & $0.18(1.06)$ \\
\hline
\end{tabular}


Table 7 (continued)

\begin{tabular}{|c|c|c|c|}
\hline & \multicolumn{3}{|c|}{ Dependent variable: Migration Status } \\
\hline & $\begin{array}{l}\text { In Transition } \\
\text { (1) }\end{array}$ & $\begin{array}{l}\text { Moved On } \\
(2)\end{array}$ & $\begin{array}{l}\text { Displaced } \\
\text { (3) }\end{array}$ \\
\hline Sex (Male) & $2.02(0.69)$ & $0.67(0.75)$ & $1.97(0.55)$ \\
\hline Marital Status (Married) & $2.97(1.16)$ & $0.70(0.93)$ & $0.58(0.60)$ \\
\hline Junior High School & $1.33(0.64)$ & $1.48(0.75)$ & $1.44(0.52)$ \\
\hline Senior High School + & $0.62(0.62)$ & $0.56(0.63)$ & $0.57(0.50)$ \\
\hline Income: 500,001-800,000 RP & $0.91(0.70)$ & $0.28(0.94)$ & $0.77(0.53)$ \\
\hline Income: $800,001-1,000,000 \mathrm{RP}$ & $2.20(0.64)$ & $0.73(0.82)$ & $1.01(0.55)$ \\
\hline Income: $1,000,000+\mathrm{RP}$ & $0.76(0.74)$ & $3.81 *(0.64)$ & $0.68(0.58)$ \\
\hline Residence Duration & $0.83(0.60)$ & $0.54(0.73)$ & $0.40(0.52)$ \\
\hline Environmental Hazards & $0.72(0.36)$ & $1.05(0.37)$ & $1.20(0.27)$ \\
\hline Medium Destruction & $7.80^{* *}(0.68)$ & $3.06(0.74)$ & $6.98 * * *(0.56)$ \\
\hline High Destruction & $3.98(0.99)$ & $4.13(0.93)$ & $106.19 * * *(0.58)$ \\
\hline Fears Nature's Wrath & $0.99(0.52)$ & $2.08(0.61)$ & $1.28(0.43)$ \\
\hline Residence Damaged & $1.08(0.63)$ & $1.79(0.63)$ & $4.52 * *(0.48)$ \\
\hline Constant & $0.04 *(1.51)$ & $0.20(1.30)$ & $0.11 *(0.96)$ \\
\hline Akaike Inf. Crit & 571.54 & 571.54 & 571.54 \\
\hline
\end{tabular}

Note:* $\mathrm{p}<0.05 ;{ }^{* *} \mathrm{p}<0.01 ;{ }^{* * *} \mathrm{p}<0.001$.

Table 8

Multinomial Logistic Regression Results for Migration Status and All Types of Recovery Aid

\begin{tabular}{|c|c|c|c|}
\hline & \multicolumn{3}{|c|}{ Dependent variable: Migration Status } \\
\hline & $\begin{array}{l}\text { In Transition } \\
\text { (1) }\end{array}$ & $\begin{array}{l}\text { Moved On } \\
(2)\end{array}$ & $\begin{array}{l}\text { Displaced } \\
(3)\end{array}$ \\
\hline Financial Aid & $0.64(0.63)$ & $15.27^{* * *}(0.69)$ & $5.03^{* * *}(0.49)$ \\
\hline HealthAid & $1.14(0.60)$ & $2.93(0.72)$ & $4.16 *(0.57)$ \\
\hline FoodAid & $0.73(0.59)$ & $0.38(0.68)$ & $0.48(0.54)$ \\
\hline Remittances & $0.36(0.87)$ & $1.36(0.76)$ & $0.60(0.63)$ \\
\hline Age: $31-40$ & $0.18(1.23)$ & $0.85(0.78)$ & $1.07(0.70)$ \\
\hline Age: $41-50$ & $0.93(0.81)$ & $0.36(0.76)$ & $0.93(0.70)$ \\
\hline Age: $51-60$ & $0.63(0.87)$ & $0.05 *(1.25)$ & $0.72(0.72)$ \\
\hline Age: $61-70$ & $1.19(0.89)$ & $0.28(1.26)$ & $0.81(0.78)$ \\
\hline Age: $70+$ & $2.11(1.16)$ & $0.73(1.46)$ & $0.38(1.11)$ \\
\hline Sex (Male) & $1.96(0.71)$ & $0.60(0.84)$ & $1.74(0.58)$ \\
\hline Marital Status (Married) & $3.56(1.20)$ & $0.44(1.00)$ & $0.40(0.63)$ \\
\hline Junior High School & $1.52(0.66)$ & $1.19(0.86)$ & $1.32(0.57)$ \\
\hline Senior High School + & $0.62(0.64)$ & $0.41(0.71)$ & $0.53(0.55)$ \\
\hline Income: $500,001-800,000 \mathrm{RP}$ & $0.97(0.72)$ & $0.31(0.97)$ & $0.74(0.58)$ \\
\hline Income: $800,001-1,000,000 \mathrm{RP}$ & $2.49(0.67)$ & $1.02(0.88)$ & $1.28(0.60)$ \\
\hline Income: $1,000,000+\mathrm{RP}$ & $0.80(0.75)$ & $5.67 *(0.75)$ & $0.82(0.62)$ \\
\hline Residence Duration & $0.91(0.62)$ & $0.43(0.82)$ & $0.36(0.55)$ \\
\hline Environmental Hazards & $0.69(0.38)$ & $0.93(0.42)$ & $1.12(0.29)$ \\
\hline Medium Destruction & $9.39 * *(0.76)$ & $2.06(0.77)$ & $5.11^{* *}(0.58)$ \\
\hline High Destruction & $3.50(1.05)$ & $4.09(1.01)$ & $124.35^{* * *}(0.65)$ \\
\hline Fears Nature's Wrath & $0.80(0.55)$ & $3.25(0.66)$ & $1.73(0.47)$ \\
\hline Residence Damaged & $1.08(0.66)$ & $1.22(0.69)$ & $3.41 *(0.51)$ \\
\hline Constant & $0.05(1.55)$ & $0.07(1.47)$ & $0.04 * *(1.11)$ \\
\hline Akaike Inf. Crit & 548.77 & 548.77 & 548.77 \\
\hline
\end{tabular}

Note: ${ }^{*} \mathrm{p}<0.05 ; * * \mathrm{p}<0.01 ; * * * \mathrm{p}<0.001$.

Table 9

Multinomial Logistic Regression Results for Migration Status and Economic Resource Assistance

\begin{tabular}{llll}
\hline & \multicolumn{2}{l}{ Dependent variable: Migration Status } \\
\cline { 2 - 3 } & $\begin{array}{lll}\text { In Transition } \\
(1)\end{array}$ & $\begin{array}{l}\text { Moved On } \\
(2)\end{array}$ & $\begin{array}{l}\text { Displaced } \\
(3)\end{array}$ \\
\hline Economic Resource Assistance: Both & $0.00^{* * *}(0.0000)$ & $17.91^{* *}(1.00)$ & $4.34(0.84)$ \\
Economic Resource Assistance: Remittances & $0.60(0.90)$ & $1.32(1.27)$ & $0.38(1.08)$ \\
Economic Resource Assistance: Financial Aid & $0.68(0.60)$ & $11.72^{* * *}(0.68)$ & $4.65^{* * *}(0.46)$ \\
Age: $31-40$ & $0.17(1.23)$ & $0.69(0.77)$ & $0.94(0.67)$ \\
Age: 41-50 & $0.88(0.82)$ & $0.36(0.75)$ & $0.86(0.67)$ \\
Age: 51-60 & $0.64(0.86)$ & $0.04 *(1.22)$ & $0.56(0.70)$ \\
Age: $61-70$ & $1.12(0.90)$ & $0.25(1.27)$ & $0.71(0.78)$ \\
Age: $70+$ & $1.82(1.14)$ & $0.42(1.37)$ & $0.29(1.06)$ \\
Sex (Male) & $1.95(0.70)$ & $0.73(0.83)$ & $1.91(0.58)$ \\
Marital Status (Married) & $3.83(1.20)$ & $0.48(0.98)$ & $0.46(0.61)$ \\
Junior High School & $1.50(0.66)$ & $0.91(0.83)$ & $1.04(0.56)$ \\
Senior High School + & $0.68(0.64)$ & $0.35(0.71)$ & $0.41(0.54)$ \\
& & & (continued on next page)
\end{tabular}


Table 9 (continued)

\begin{tabular}{|c|c|c|c|}
\hline & \multicolumn{3}{|c|}{ Dependent variable: Migration Status } \\
\hline & $\begin{array}{l}\text { In Transition } \\
\text { (1) }\end{array}$ & $\begin{array}{l}\text { Moved On } \\
\text { (2) }\end{array}$ & $\begin{array}{l}\text { Displaced } \\
\text { (3) }\end{array}$ \\
\hline Income: $500,001-800,000 \mathrm{RP}$ & $1.00(0.72)$ & $0.33(0.96)$ & $0.78(0.57)$ \\
\hline Income: $800,001-1,000,000 \mathrm{RP}$ & $2.49(0.65)$ & $0.84(0.86)$ & $1.07(0.58)$ \\
\hline Income: $1,000,000+\mathrm{RP}$ & $0.80(0.74)$ & $5.01 *(0.73)$ & $0.79(0.62)$ \\
\hline Residence Duration & $0.95(0.61)$ & $0.43(0.83)$ & $0.34(0.56)$ \\
\hline Environmental Hazards & $0.68(0.37)$ & $0.95(0.41)$ & $1.16(0.29)$ \\
\hline Medium Destruction & $9.47 * *(0.74)$ & $2.48(0.77)$ & $5.89 * *(0.57)$ \\
\hline High Destruction & $3.51(1.03)$ & $3.98(0.98)$ & $106.59^{* * *}(0.62)$ \\
\hline Fears Nature's Wrath & $0.85(0.55)$ & $3.28(0.66)$ & $1.60(0.46)$ \\
\hline Residence Damaged & $1.12(0.65)$ & $1.34(0.68)$ & $3.99 * *(0.50)$ \\
\hline Constant & $0.04 *(1.55)$ & $0.10(1.43)$ & $0.08 *(1.01)$ \\
\hline Akaike Inf. Crit & 549.43 & 549.43 & 549.43 \\
\hline
\end{tabular}

Table 10

Multinomial Logistic Regression Results for Migration Status and Resource Recovery Assistance

\begin{tabular}{|c|c|c|c|}
\hline & \multicolumn{3}{|c|}{ Dependent variable: Migration Status } \\
\hline & $\begin{array}{l}\text { In Transition } \\
\text { (1) }\end{array}$ & $\begin{array}{l}\text { Moved On } \\
\text { (2) }\end{array}$ & $\begin{array}{l}\text { Displaced } \\
\text { (3) }\end{array}$ \\
\hline Resource Recovery Assistance: Both & $0.69(0.58)$ & $2.81(0.69)$ & $3.49 *(0.55)$ \\
\hline Resource Recovery Assistance: Health Aid & $0.87(0.80)$ & $3.13(0.89)$ & $3.36(0.73)$ \\
\hline Resource Recovery Assistance: Food Aid & $0.56(0.89)$ & $1.60(0.92)$ & $0.46(1.00)$ \\
\hline Age: $31-40$ & $0.22(1.22)$ & $0.51(0.70)$ & $0.90(0.66)$ \\
\hline Age: $41-50$ & $1.26(0.78)$ & $0.34(0.71)$ & $0.91(0.67)$ \\
\hline Age: $51-60$ & $0.74(0.85)$ & $0.05 *(1.19)$ & $0.64(0.69)$ \\
\hline Age: $61-70$ & $1.50(0.88)$ & $0.22(1.22)$ & $0.84(0.75)$ \\
\hline Age: $70+$ & $2.41(1.21)$ & $0.36(1.38)$ & $0.26(1.13)$ \\
\hline Sex (Male) & $1.86(0.70)$ & $0.56(0.75)$ & $1.60(0.55)$ \\
\hline Marital Status (Married) & $3.66(1.19)$ & $0.59(0.93)$ & $0.47(0.62)$ \\
\hline Junior High School & $1.45(0.65)$ & $1.70(0.76)$ & $1.72(0.53)$ \\
\hline Senior High School + & $0.59(0.63)$ & $0.63(0.65)$ & $0.66(0.52)$ \\
\hline Income: 500,001-800,000 RP & $0.83(0.70)$ & $0.27(0.96)$ & $0.77(0.55)$ \\
\hline Income: $800,001-1,000,000 \mathrm{RP}$ & $2.13(0.66)$ & $0.77(0.83)$ & $1.22(0.57)$ \\
\hline Income: $1,000,000+\mathrm{RP}$ & $0.72(0.74)$ & $4.27 *(0.66)$ & $0.73(0.59)$ \\
\hline Residence Duration & $0.85(0.60)$ & $0.56(0.72)$ & $0.43(0.52)$ \\
\hline Environmental Hazards & $0.74(0.37)$ & $1.01(0.38)$ & $1.17(0.28)$ \\
\hline Medium Destruction & $7.31 * *(0.70)$ & $3.03(0.75)$ & $6.81^{* * *}(0.57)$ \\
\hline High Destruction & $3.71(1.01)$ & $5.03(0.92)$ & $126.99 * * *(0.61)$ \\
\hline Fears Nature's Wrath & $0.94(0.53)$ & $2.26(0.62)$ & $1.38(0.45)$ \\
\hline Residence Damaged & $1.17(0.64)$ & $1.53(0.63)$ & $3.59 *(0.50)$ \\
\hline Constant & $0.04 *(1.54)$ & $0.12(1.35)$ & $0.05^{* *}(1.09)$ \\
\hline Akaike Inf. Crit & 572.92 & 572.92 & 572.92 \\
\hline
\end{tabular}

Note:* $\mathrm{p}<0.05 ;{ }^{* *} \mathrm{p}<0.01 ; * * * \mathrm{p}<0.001$.

Table 11

Multinomial Logistic Regression Results for Migration Status and Household Recovery Assistance

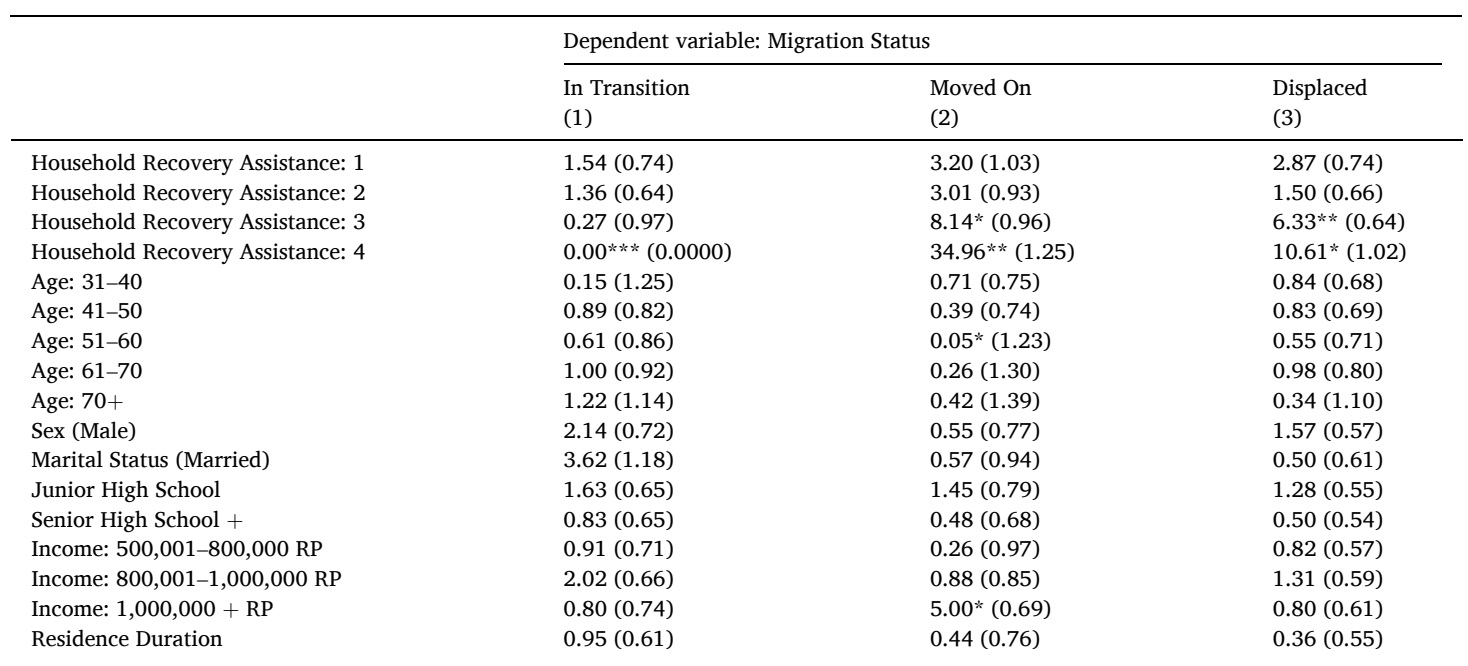




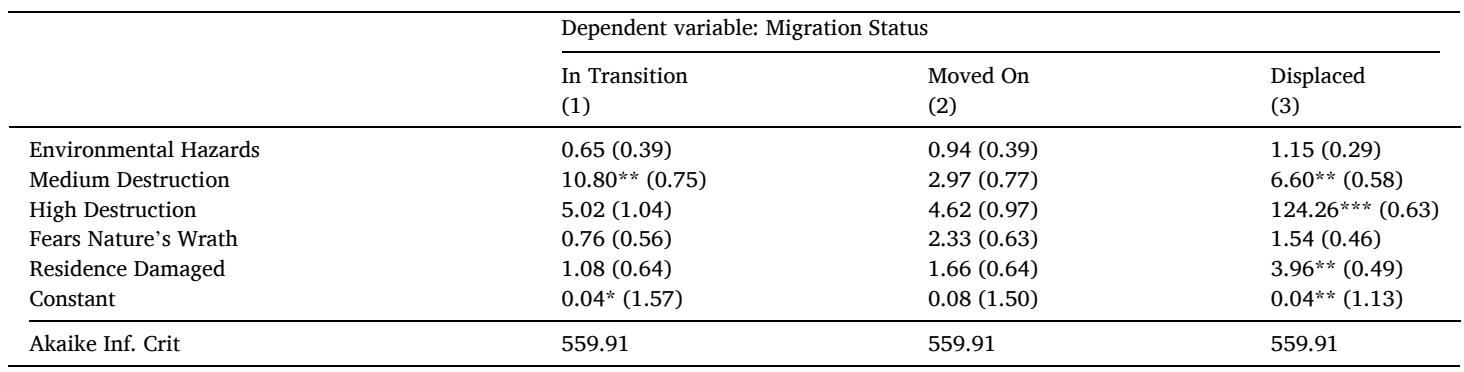

Note: $\mathrm{p}<0.05 ; \mathrm{p}<0.01 ;{ }^{* * *} \mathrm{p}<0.001$.

\section{References}

[1] L.M. Hunter, Migration and environmental hazards, Popul. Environ. 26 (4) (2005) 273-302.

[2] S.L. Cutter, B.J. Boruff, W.L. Shirley, Social vulnerability to environmental hazards, Soc. Sci. Q. 84 (2) (2003) 242-261.

[3] E. Fussell, N. Sastry, M. VanLandingham, Race, socioeconomic status, and return migration to new orleans after hurricane katrina, Popul. Environ. 31 (1-3) (2010) 20-42.

[4] G. Hugo, Environmental concerns and international migration, Int. Migr. Rev. (1996) 105-131.

[5] C.A. Myers, T. Slack, J. Singelmann, Social vulnerability and migration in the wake of disaster: the case of hurricanes katrina and rita, Popul. Environ. 29 (6) (2008) $271-291$.

[6] N. Sastry, J. Gregory, The location of displaced new orleans residents in the year after hurricane katrina, Demography 51 (3) (2014) 753-775.

[7] C. Amin, S. Sukamdi, R. Rijanta, Exploring typology of residents staying in disaster prone areas: a case study in tambak lorok, semarang, Indonesia, Forum Geogr. 32 (1) (2018).

[8] S. Hidayati, A Year after the 2010 Merapi Eruption: Volcano Hazard and Indonesian Government Mitigation Measures, 2011. http://miavita.brgm.fr/pre ssroom/Pages/ayearafterthe2010Merapieruption.aspx.

[9] M.B. Rahman, I.S. Nurhasanah, S.P. Nugroho, Community resilience: learning from mt merapi eruption 2010, Procedia-Soc. Behav. Sci. 227 (2016) 387-394.

[10] A. Sontosudarmo, Persepsi pengungsi merapi dalam transmigrasi, Maj. Geogr. Indones. 10 (18) (1996) 37-57.

[11] E.S. Lee, A theory of migration, Demography 3 (1) (1966) 47-57.

[12] A.M. Findlay, J. Wahba, Migration and demographic change, Popul. Space Place 19 (6) (2013) 651-656.

[13] S. Preston, P.H. Heveline, M. Guillot, Demography: Measuring and Modeling Population Processes, first ed., Wiley-Blackwell, Malden, MA, 2000.

[14] J. DaVanzo, Micro Economic Approaches to Studying Migration Decisions, Rand, New York, NY, 1980.

[15] G.F. De Jong, J. Fawcett, Multidisciplinary frameworks and models of migration decision making, in: Migration Decision Making: Multidisciplinary Approaches to Microlevel Studies in Developed and Developing Countries, Elsevier, Elmsford, New York, 1981.

[16] D.S. Massey, J. Arango, G. Hugo, A. Kouaouci, A. Pellegrino, J.E. Taylor, Theories of international migration: a review and appraisal, Popul. Dev. Rev. 19 (3) (1993) $431-466$.

[17] R. Elmhirst, Displacement, resettlement, and multi-local livelihoods: positioning migrant legitimacy in lampung, Indonesia, Crit. Asian Stud. 44 (1) (2012) $131-152$.

[18] J. Van Lottum, D. Marks, The determinants of internal migration in a developing country: quantitative evidence for Indonesia, 1930-2000, Appl. Econ. 44 (34) (2012) 4485-4494.

[19] M. Czaika, M. Vothknecht, Migration and aspirations-are migrants trapped on a hedonic treadmill? IZA Journal of Migr. 3 (1) (2014) 1.

[20] G.J. Hugo, Circular migration in Indonesia, Popul. Dev. Rev. (1982) 59-83.

[21] D. Forbes, Mobility and uneven development in Indonesia: a critique of explanations of migration and circular migration, in: Population Mobility and Development: Southeast Asia and the Pacific, vol. 1981, Canberra Australia Australian National University, 1981.

[22] J.A. Lindquist, The Anxieties of Mobility: Migration and Tourism in the Indonesian Borderlands, University of Hawaii Press, 2009.

[23] J.-P. Cassarino, Theorising return migration: the conceptual approach to return migrants revisited, Int. J. Multicult. Soc. 6 (2) (2004) 253-279.

[24] O. Stark, The Migration of Labor, Basil Blackwell, Inc, 1991.

[25] O. Stark, On the microeconomics of return migration, in: Trade and Development, Springer, 1996, pp. 32-41.

[26] J.E. Taylor, Development Strategy, Employment and Migration: Insights from Models, vol. 1996, Paris France Organisation for Economic Co-operation and Development [OECD, 1996.

[27] R.W. Gardner, Macrolevel influences on the migration decision process, in: Migration Decision Making: Multidisciplinary Approaches to Microlevel Studies in Developed and Developing Countries, Pergamon, New York, 1981.
[28] J.C. Belcher, F.L. Bates, Aftermath of natural disasters: coping through residential mobility, Disasters 7 (2) (1983) 118-128.

[29] W. Petersen, A general typology of migration, Am. Sociol. Rev. 23 (3) (1958) 256-266.

[30] W. Petersen, Population, MacMillian Publishing Company, New York, NY, 1975.

[31] R.J. Nawrotzki, H. Brenkert-Smith, L.M. Hunter, P.A. Champ, Wildfire-migration dynamics: lessons from Colorado's fourmile canyon fire, Soc. Nat. Resour. 27 (2) (2014) 215-225.

[32] R. Rogers, The future of refugee flows and policies, Int. Migr. Rev. (1992) 1112-1143.

[33] C. Gray, E. Frankenberg, T. Gillespie, C. Sumantri, D. Thomas, Studying displacement after a disaster using large-scale survey methods: sumatra after the 2004 tsunami, Ann. Assoc. Am. Geogr. 104 (3) (2014) 594-612.

[34] R. Ruben, M. Van Houte, T. Davids, What determines the embeddedness of forcedreturn migrants? rethinking the role of pre-and post-return assistance, Int. Migr. Rev. 43 (4) (2009) 908-937.

[35] P.B. Reagan, R.J. Olsen, You can go home again: evidence from longitudinal data, Demography 37 (3) (2000) 339-350.

[36] N.S. Bryner, M. Garcia-Lozano, C. Bruch, Washed out: policy and practical considerations affecting return after hurricane katrina and superstorm sandy, J. Asian Dev. 3 (1) (2017) 73-93.

[37] S. Karimi, Return migration after 30 september 2009 earthquake in west sumatra, Indonesia, J. Asian Dev. 3 (1) (2017) 144-155.

[38] L.P. Boustan, M.E. Kahn, P.W. Rhode, Moving to higher ground: migration response to natural disasters in the early twentieth century, Am. Econ. Rev. 102 (3) (2012) 238-244.

[39] B.K. Paul, Coping with the 1996 tornado in tangail, Bangladesh: an analysis of field data, Prof. Geogr. 50 (3) (1998) 287-301.

[40] B.K. Paul, Evidence against disaster-induced migration: the 2004 tornado in northcentral Bangladesh, Disasters 29 (4) (2005) 370-385.

[41] J.R. Stevenson, H. Kachali, Z. Whitman, E. Seville, J. Vargo, T. Wilson, Preliminary observations of the impacts the 22 february christchurch earthquake had on organisations and the economy: a report from the field ( 22 february- 22 march 2011), Bull. N. Z. Soc. Earthq. Eng. 44 (2) (2011) 65.

[42] J. Stevenson, J. Vargo, E. Seville, H. Kachali, A. McNaughton, F. Powell, The Recovery of Canterbury's Organisations: A Comparative Analysis of the 4 September 2010, 22 February and 13 June 2011 Earthquake, Technical report, University of Canterbury. Civil and Natural Resources Engineering, 2012.

[43] P. Willroth, J.R. Diez, N. Arunotai, Modelling the economic vulnerability of households in the phang-nga province (Thailand) to natural disasters, Nat. Hazards 58 (2) (2011) 753-769.

[44] N. Weng Chan, Flood disaster management in Malaysia: an evaluation of the effectiveness of government resettlement schemes, Disaster Prev. Manag.: Int. J. 4 (4) (1995) 22-29.

[45] R.A. McLeman, Settlement abandonment in the context of global environmental change, Glob. Environ. Chang. 21 (2011) S108-S120.

[46] J.L. Rozdilsky, Second hazards assessment and sustainable hazards mitigation: disaster recovery on Montserrat, Nat. Hazards Rev. 2 (2) (2001) 64-71.

[47] R.S. Pasupuleti, Designing culturally responsive built environments in post disaster contexts: tsunami affected fishing settlements in tamilnadu, India, Int. J. Disaster Risk Reduct. 6 (2013) 28-39.

[48] K. Huda, N. Yamamoto, N. Maki, S. Funo, Rehabilitation of urban settlements in the early reconstruction stage after a tsunami-a case study of banda aceh municipality in Indonesia-, J. Asian Architect. Build Eng. 6 (1) (2007) 103-110.

[49] R.S. Oktari, K. Munadi, S. Arief, I.Z. Fajri, et al., Changes in coastal land use and the reasons for selecting places to live in banda aceh 10 years after the 2004 indian ocean tsunami, Nat. Hazards 88 (3) (2017) 1503-1521.

[50] P.D. Little, K. Smith, B.A. Cellarius, D.L. Coppock, C. Barrett, Avoiding disaster: diversification and risk management among east african herders, Dev. Change 32 (3) (2001) 401-433.

[51] M. Ezra, G.-E. Kiros, Rural out-migration in the drought prone areas of Ethiopia: a multilevel analysis, Int. Migr. Rev. 35 (3) (2001) 749-771.

[52] A. Oliver-Smith, Post-disaster housing reconstruction and social inequality: a challenge to policy and practice, Disasters 14 (1) (1990) 7-19.

[53] S. Bailey, P. Harvey, State of evidence on humanitarian cash transfers, in: Background Note for the Background Note for the High Level Panel on Humanitarian Cash Transfers, Overseas Development Institute, 2015. 
[54] C.A. Johnson, K. Krishnamurthy, Dealing with displacement: can "social protection" facilitate long-term adaptation to climate change? Glob. Environ. Chang. 20 (4) (2010) 648-655.

[55] L. Bolton, Cash-Transfers for Long-Term Resilience in Conflict Affected Contexts, 2016.

[56] J. Hoddinott, D. Gilligan, M. Hidrobo, A. Margolies, S. Roy, S. Sandström, B. Schwab, J. Upton, Enhancing Wfp's Capacity and Experience to Design, Implement, Monitor, and Evaluate Vouchers and Cash Transfer Programmes: Study Summary, International Food Policy Research Institute, Washington, DC, 2013.

[57] P. Pozarny, Evidence on the Comparative Cost Efficiency and Effectiveness of Varying Social Assistance Modalities, Technical report, Helpdesk Research Report, 2016.

[58] L. Suryadinata, E.N. Arifin, A. Ananta, Indonesia's Population: Ethnicity and Religion in a Changing Political Landscape, Institute of Southeast Asian Studies, 2003.

[59] N. Napsiah, B. Gunawan, O.S. Abdoellah, M. Sulaeman, Value rationality of people living on the slope of merapi in yogyakarta, Analisa: J. Soc. Sci. Relig. 1 (1) (2016) 105-120.

[60] Sukamto, Mengenang sepuluh tahun bencana industri lumpur lapindo dan tindakan kolektif para korban, Jurnal Teori Dan Pembelajaran IPS 1 (1) (2016) $52-64$.

[61] B.P. Statistik, Sensus Penduduk 2010, Badan Pusat Statistik, Jakarta, Indonesia, 2010.
[62] S.R. Curran, S. Shafer, K.M. Donato, F. Garip, Mapping gender and migration in sociological scholarship: is it segregation or integration? Int. Migr. Rev. 40 (1) (2006) 199-223.

[63] R. Elmhirst, Tigers and gangsters: masculinities and feminised migration in Indonesia, Popul. Space Place 13 (3) (2007) 225-238.

[64] P.F. Kelly, Migration, agrarian transition, and rural change in southeast asia: introduction, Crit. Asian Stud. 43 (4) (2011) 479-506.

[65] J.D. Kasarda, M. Janowitz, Community attachment in mass society, Am. Sociol. Rev. (1974) 328-339.

[66] R Core Team, R: a Language and Environment for Statistical Computing, R Foundation for Statistical Computing, Vienna, Austria, 2013, ISBN 3-900051-07-0.

[67] R.W. Perry, What is a disaster?, in: Handbook of Disaster Research Springer, 2007, pp. $1-15$.

[68] E.L. Quarantelli, R.R. Dynes, Response to social crisis and disaster, Annu. Rev. Sociol. (1977) 23-49.

[69] A. Press, Indonesia's Mount Merapi Erupts, Prompting Evacuations, 2018. htt ps://weather.com/news/news/2018-05-11-mount-merapi-eruption-indonesia.

[70] V. Junge, J.R. Diez, L. Schätzl, Determinants and consequences of internal return migration in Thailand and vietnam, World Dev. 71 (2015) 94-106.

[71] K. Erikson, Everything in its Path: Destruction of Community in the Buffalo Creek Flood, Simon and Schuster, New York, NY, 1978. 